\title{
Moderate alcohol use and health: A consensus document
}

\author{
A. Poli ${ }^{a, *}$, F. Marangoni ${ }^{\text {a }}$, A. Avogaro ${ }^{\text {b }}$, G. Barba ${ }^{\text {, }}$, \\ S. Bellentani ${ }^{\text {d }}$, M. Bucci ${ }^{e}$, R. Cambieri ${ }^{f}$, A.L. Catapano ${ }^{g}$, \\ S. Costanzo ${ }^{\text {h }}$, C. Cricelli ${ }^{i}$, G. de Gaetano ${ }^{j}$, \\ A. Di Castelnuovo ${ }^{k}$, P. Faggiano ', F. Fattirolli ${ }^{m}$, L. Fontana ${ }^{\text {n }}$, G. Forlani ${ }^{\circ}$, \\ S. Frattini ${ }^{\text {P }}$, R. Giacco ${ }^{\mathrm{q}}$, C. La Vecchia ${ }^{r}$, L. Lazzaretto ${ }^{\mathrm{s}}$, L. Loffredo ${ }^{\mathrm{t}}$, \\ L. Lucchin u, G. Marelli v, W. Marrocco s, S. Minisola w, M. Musicco ${ }^{x}$, S. Novo y, \\ C. Nozzoli ${ }^{\text {, }}$ C. Pelucchi ${ }^{r}$, L. Perri ${ }^{\text {t }}$, F. Pieralli ${ }^{z}$, D. Rizzoni ${ }^{\text {aa }}$, R. Sterzi ${ }^{\text {ab }}$, \\ R. Vettor ${ }^{\text {ac }}$, F. Violi ${ }^{\mathrm{t}}$, F. Visioli ${ }^{\text {ad }}$
}

${ }^{a}$ NFI (Nutrition Foundation of Italy), Viale Tunisia 38, 20124 Milan, Italy

b SIPREC (Italian Society for Cardiovascular Prevention) and University of Padova, Italy

c SIIA (Italian Society of Hypertension), Institute of Food Science - Italian National Research Council - CNR, Avellino, Italy

'Gastroenterology and Liver Center, Local Health Agency of Modena, "Ramazzini" Hospital, Carpi, Italy

e SISA (Italian Society for the Study of Atherosclerosis) and Clinical Research Center Ce.S.I. "Università G. d'Annunzio"

Foundation, University of Chieti, Italy

f SNAMID (National Society of Medical Education), Milan, Italy

${ }^{g}$ SITECS (Italian Society for Clinical and Experimental Therapy) and Department of Pharmacology and Biomolecular Sciences, University of Milan, Italy

${ }^{\mathrm{h}}$ Laboratory of Genetic and Environmental Epidemiology, Catholic University, Campobasso, Italy

'SIMG (Italian Society of General Medicine), Florence, Italy

${ }^{j}$ Research Laboratories, "John Paul II" Foundation for Research and Treatment, Catholic University, Campobasso, Italy

k Laboratory of Genetic and Environmental Epidemiology, "John Paul II" Foundation for Research and Treatment, Catholic University, Campobasso, Italy

'ANMCO (Italian National Association of Hospital Cardiologists) and Chair of Cardiology, University of Brescia, Italy

m ANMCO (Italian National Association of Hospital Cardiologists), Careggi Hospital and University of Florence, Italy

${ }^{n}$ AMD (Italian Association of Diabetologists), Dietology, Diabetology and Metabolic Diseases Unit, Sandro Pertini Hospital, Rome, Italy

${ }^{\circ}$ AMD (Italian Association of Diabetologists), Unit of Metabolic Diseases \& Clinical Dietetics Alma Mater Studiorum, University of Bologna, Italy

${ }^{\mathrm{P}}$ ANMCO (Italian National Association of Hospital Cardiologist) and Cardiology Unit - Istituti Ospitalieri di Cremona, Italy

" SID (Italian Society of Diabetology) and Institute of Food Science - National Research Council-CNR, Avellino, Italy

r "Mario Negri" Pharmacological Research Institute and Department of Clinical Sciences and Community Health, University of Milan, Italy

\footnotetext{
* Corresponding author.

E-mail address: poli@nutrition-foundation.it (A. Poli).
} 
${ }^{\mathrm{s}}$ FIMMG (Italian Federation of General Medicine Doctors), Rome, Italy

${ }^{\mathrm{t}}$ SIMI (Italian Society of Internal Medicine), Department of Internal Medicine and Medical Specialties, University of Rome

"La Sapienza", Italy

${ }^{\mathrm{u}} \mathrm{ADI}$ (Italian Association of Dietetics), Dietetics and Clinical Nutrition Unit, Bolzano Health District, Bolzano, Italy

${ }^{\vee}$ AMD (Italian Association of Diabetologists), Diabetology and Metabolic Diseases Unit, Desio and Vimercate Hospital, Italy

${ }^{\mathrm{w}}$ SIOMMMS (Italian Society of Osteoporosis Mineral Metabolism and Skeletal Diseases), Department of Internal Medicine and Medical Disciplines, University of Rome "Sapienza", Italy

${ }^{x}$ CNR-ITB (Institute of Biomedical Technologies of the National Research Council), Milan, Italy

${ }^{y}$ SIC (Italian Society of Cardiology), Chair of Cardiovascular Diseases, Department of Biomedicine, Internal and Specialities (DIBIMIS), University of Palermo, Italy

${ }^{\mathrm{z}}$ FADOI (Italian Federation of the Associations of Internal Medicine Physicians), University Hospital Careggi, Florence, Italy

aa SIIA (Italian Society of Hypertension), Department of Clinical and Experimental Sciences, University of Brescia, Italy

ab The Italian Stroke Forum, Azienda Ospedaliera Niguarda Cà Granda, Milan, Italy

ac SIO (Italian Society of Obesity), Department of Medical and Surgical Sciences, Azienda Ospedaliera-University of Padova, Italy

${ }^{\text {ad }}$ Laboratory of Functional Foods, Madrid Institute for Advanced Studies (IMDEA) - Food, CEI UAM + CSIC, Madrid, Spain

Received 13 November 2012; received in revised form 29 January 2013; accepted 27 February 2013

Available online 1 May 2013

KEYWORDS
Alcohol;
Cardiovascular
disease;
Cancer;
Prevention;
Polyphenols;
Diabetes;
Metabolic syndrome;
Cognitive decline;
Overall mortality

Alcoholic beverages are being consumed for millennia: humans drink them for pleasure, for their energy content or for behavioural and ritual reasons. Starting from the second half of the last century, an increasing number of studies mostly epidemiological in nature - carefully examined the associations between consumption of alcohol and human health. The general view, at that time, was that, while excessive alcohol consumption is noxious and clearly associated with increased incidence of disease, moderate consumption might be associated with reduced cardiovascular risk. Further studies associated moderate consumption of alcohol with reduced incidence also of metabolic and neurodegenerative diseases. Conversely, a positive association has been reported with increased risk of developing some neoplasias. The World Health Organization (WHO) has a 'zero tolerance' policy on alcohol consumption, but an intense scientific debate is currently taking place to confirm or dispute such an approach.

The aim of this consensus paper is to review the available evidence on the association between moderate alcohol use, health and disease and to provide a working document to the scientific and health professional communities.

\section{Methodology}

The Nutrition Foundation of Italy coordinated a team of Italian experts, as follows: selected Italian scientific societies were contacted and required to provide topic-specific reviews of the alcohol-health relation. Twenty societies out of 23 agreed (see Appendix 1), although one finally chose not to contribute to this document. All contributions were 
merged, discussed and agreed upon by the entire Panel, which approved the final paper in September 2012.

\section{Methodological limitations in the assessment of alcohol-health associations}

All studies on the associations between alcohol and health are methodologically complex. This is due to the methods used to assess alcohol consumption, to the choice of control groups and to the correct definition of confounding factors. Assessment of alcohol consumption is usually done by specific questionnaires, where frequency and amount of consumption are collected. This procedure often underestimates the true rate of consumption, especially in heavy drinkers, who tend to report lower-than-habitual use [1]. Such evaluation bias raises some interpretation issues: a) when excessive alcohol consumption is found to have untoward effects, these are attributed to intakes that are lower than that inducing the effects and b) concerning healthy effects attributed to moderate alcohol consumption, an underestimation of 'optimal' intake and of the minimal levels at which the benefits would disappear, will be computed [2].

Because the alcohol-health association not only depends on quantities but also on patterns of alcohol use (in other words, whether intakes are concentrated on times such as the weekends or are regularly spread during weekly meals), it is also important to clearly take such patterns into account in addition to the mere quantities [1,2]

The selection of control groups is crucial in studies that associate alcohol and health. Usually, abstainers are chosen as the reference group, whereas drinkers are classified based on levels of intake. However, the group of 'abstainers' often includes subjects who report rare though not nil consumption. Given that such subjects may underreport their intakes, the contribution of their inclusion among the controls to the overall effect might not be negligible [3]. Former drinkers too are often included in the teetotallers' group. Notably, those who quit drinking often do so because of health reasons. The inclusion of these subjects in control groups might place the latter at a false higher risk level ('sick-quitter hypothesis') [4]. Therefore, ex-drinkers should only be included in ad-hoc categories. Moderate consumption of alcoholic beverages has often been associated with healthier lifestyles and higher socioeconomic status (though with cigarette smoking too) [5]. These associations might explain, at least in part, the apparent reduced risk of cardiovascular disease (CVD) and overall mortality in moderate drinkers vs. teetotallers [4]. In any event, these important confounding factors should be carefully taken into account when performing or analysing association studies $[3,4]$.

Another caveat in statements on alcohol and health is related to the current absence of randomised clinical trials. Indeed, all currently available data are based on observational studies. While randomised clinical trials would eventually contribute to better clarify the role of alcohol in human health, such studies are obviously very difficult to perform for both practical and ethical reasons $[3,4,6]$.

In summary, epidemiological analyses of the association between alcohol and health are complex and require keen attention to the various confounders, bias, and methodological issues that might lead to unsound conclusions.

\section{Alcohol and CVD disease}

\section{Coronary heart disease and fatal arrhythmia}

Data derived from epidemiological studies and obtained in primary care individuals consistently show the existence of a significant inverse association between moderate alcohol use and cardiovascular risk (mainly, myocardial infarction and stroke). Conversely, excessive intake does increase cardiovascular risk. Several meta-analyses reported a 'J'shaped curve that describes the association between alcohol consumption and cardiovascular risk, namely a higher risk associated to both abstention and excessive intakes as compared with moderate consumption. The maximal reduction of cardiovascular risk (fatal and nonfatal events) associated with moderate consumption has been estimated to be approximately $30 \%$.

In some studies, actually, the inverse association between alcohol use and infarction risk reduction appeared to be linear, that is increasing alcohol consumption correlated with a continually decreasing risk. Such association was observed, as an example, in the Health Professional cohort [5], in which maximum protection was observed in consumers of $50 \mathrm{~g}$ or more of alcohol, that is four drinks ${ }^{1}$ per day. A recent meta-analysis [7] reported a "J" association in women but not in men, in whom higher levels of intake were associated with lower coronary risk. In this meta-analysis, the protective effect was seen in all age groups, even though risk reduction - in absolute terms - increased with age. In the most recent meta-analysis by Ronksley et al. [8], consumption of alcoholic beverages was associated with a $25-50 \%$ reduction of fatal and nonfatal coronary event risk as compared with teetotallers. Low-to-moderate alcohol consumption was associated with a reduction of cardiovascular and all-cause risk reduction also in a cohort of 14,125 hypertensive men selected from the Physicians' Health Study [9]; a further analysis of the same cohort reported an inverse association between moderate alcohol use and incidence of coronary heart disease (CHD). In this analysis, risk reduction was $40 \%$ in subjects who drank more than eight drinks/week.

In diabetic subjects a meta-analysis of six prospective studies evidenced a close association between moderate alcohol consumption and reduced coronary disease; the reduction of relative risk (RR) was similar in magnitude to that seen in the general population and in hypertensive patients [10].

Less evidence is presently available to describe the effects of alcohol in patients with pre-existing CHD [11,12]. A recent meta-analysis of eight studies involving a total of 16,531 subjects with cardiovascular events reported that a low-to-moderate $(5-25 \mathrm{~g} / \mathrm{d})$ alcohol consumption is associated with a significantly lower incidence of cardiovascular

\footnotetext{
${ }^{1}$ By definition, one drink is a standard $\sim 150 \mathrm{ml}$ wine glass, or a can of beer, or a standard shot glass $\sim 40 \mathrm{ml}$ of liquor. This standard drink contains $\sim 12 \mathrm{~g}$ of ethanol.
} 
and all-cause mortality. These data confirm in CHD patients what has been observed in healthy subjects. A positive effect of moderate alcohol consumption was also apparent in patients who underwent angioplasty procedures, in whom both atherosclerosis progression and clinical relapses appeared to be positively influenced by alcohol intake $[6,13]$.

In the area of secondary prevention, one aspect that deserves attention is the possible interaction between alcohol and pharmacological therapy. In particular, close attention should be paid to the interaction between alcohol and anti-platelet drugs or oral anticoagulants, which can increase the risk of haemorrhages.

As far as arrhythmias are concerned, binge drinking has been associated with increased risk of atrial fibrillation, that is, the so-called 'holiday heart syndrome'. Recently, it was suggested that even the habitual intake of high alcohol doses (35 drinks/week or more) might correlate with arrhythmia risk [14-16]. A recent meta-analysis indicated a linear, dose-response association between alcohol use and risk of atrial fibrillation [17]. These data suggest that the risk of arrhythmia proportionally increases with daily doses of alcohol; presumably, a reduction of alcohol consumption or even abstinence would be associated with lower atrial fibrillation risk. Conversely, sudden death due to ventricular arrhythmias was reportedly less frequent in both men and women who consumed approximately one drink/d $[18,19]$.

In summary, as far as primary prevention is concerned, moderate alcohol use by apparently healthy individuals is associated with significant reduction of cardiovascular risk and sudden death due to ventricular arrhythmias. The presence of risk factors such as hypertension does not seem to markedly modify this association. Patients with preexisting CVD could get similar benefits from moderate alcohol consumption but should pay attention to the possible interaction of alcohol with their pharmacological regimen. Excessive alcohol consumption is specifically dangerous for patients with cardiomyopathy or supraventricular arrhythmias, being able to worsen their arrhythmic risk.

\section{Stroke}

Several prospective studies evaluated the association between alcohol consumption and risk of stroke. Most studies reported a ' $\mathrm{J}$ '-shaped association, especially concerning ischaemic strokes; because of the relatively low incidence of haemorrhagic stroke, the effects of alcohol on total strokes are similar to those observed for ischaemic strokes.

A meta-analysis of both cohort and case-control studies [20] reported a 'J'-shaped association between alcohol consumption and total and ischaemic stroke risk, while a linear positive association was observed between alcohol intake and haemorrhagic stroke. In particular, subjects who consumed $<12 \mathrm{~g}$ or between 12 and $24 \mathrm{~g} / \mathrm{d}$ of alcohol, that is one to two drinks/d were attributed a significantly reduced risk as compared with teetotallers $(R R=0.80$ and 0.72 , respectively). Higher alcohol consumption, that is more than $60 \mathrm{~g}$, or five drinks/d was conversely associated with a significant increase of both ischaemic $(R R=1.69)$ and haemorrhagic $(\mathrm{RR}=2.18)$ strokes. A more recent meta-analysis [21] confirmed these data, which were not modified following adjustment for cerebrovascular mortality and morbidity. Finally, the most recent meta-analysis on this topic [8] - which pooled a sample of hundreds of thousands of individuals - indicates that stroke risk reduction (both as mortality and incidence) is significant only in association with a daily alcohol intake between 2.5 and $14.9 \mathrm{~g}(\mathrm{RR}=0.86$ and 0.80 , respectively).

In the Reynolds et al. meta-analysis [20], stroke RR as associated with alcohol intake was also analysed for sex. Even though the ' $\mathrm{J}$ '-shaped curve was seen in both sexes, stroke RR for consumptions $>60 \mathrm{~g}$, that is five drinks/d was higher in women than in men $(R R=4.29$ and 1.76 vs. abstainers, respectively). The fact that women appear to be more sensitive to the effects of high intakes was confirmed by Ronksley et al. [8], who specifically analysed haemorrhagic stroke. However, the Nurses' Health Study (NHS) maybe because of the limited number of subjects who consumed elevated alcohol quantities - did not report such an untoward effect [22].

Few studies separately analysed the role played by different alcoholic beverages on stroke risk. The results of the Stroke Prevention in Young Women Study [23] suggest that wine exerts protective effects that were not recorded for either beer or liquor. In a meta-analysis of the effects of alcohol on cerebrovascular diseases [24], a stratified analysis also suggested protective effects of wine, but not of beer, consumption. Conversely, no significant difference was observed among the various kinds of beverages within the Framingham [25] and the Northern Manhattan Studies [26].

Data on the protective effects of moderate alcohol consumption are corroborated by the EPIC Norfolk (Norfolk cohort of European Prospective Investigation of Cancer study), where more than 20,000 subjects were followed up for over a decade. This study underscored the interaction between alcohol consumption and 'healthy' lifestyles that include abstinence from smoking, appropriate diet and physical exercise. These four features halved stroke risk as compared with people who did not follow such guidelines. The adoption of one to three of these indications reduced risk to a significantly lower extent [27].

The results of the Physician's Health Study suggest that low-to-moderate alcohol consumption and stroke-risk reduction are also associated in secondary prevention [28]. Patients who drank in moderation exhibited lower cardiovascular mortality (though not specifically for stroke) as compared with non-drinkers. It must be underlined that risk evaluation should be exerted with great care on individual bases. A recent study [29] suggests that the protective effects of moderate alcohol intake on stroke risk can be significantly attenuated in the presence of high serum concentrations of gamma-glutamyltransferase (gammaGT), which postulates an inadequate estimate of alcohol consumption or concomitant diseases that would reduce any beneficial effect.

Binge drinking [30] is usually associated with more elevated stroke risk, possibly because of the increase in blood pressure that follows large alcohol intakes [31]. Accordingly, increased risk within the first two hours of alcohol assumption has been reported at all levels of consumption [32]. Apparently, this phenomenon is transitory and, within $24 \mathrm{~h}$, risk ratios return to 'habitual' values. 
In summary, moderate consumption is associated with reduced risk of total stroke and notably of ischaemic events; conversely, consumption of elevated quantities of alcohol is an important risk factor for any type of stroke.

\section{Peripheral artery disease}

Several pieces of evidence, as discussed above [24,33,34], support an inverse association between alcohol use and acute CVD risk; conversely, the risk of developing non-acute atherosclerotic diseases in relation to alcohol use has been poorly investigated. Among such disorders, peripheral artery disease (PAD) has a high prevalence and concerns $>5 \%$ of subjects older than 60 years [35]; PAD itself is considered as a main cause of disability. Indeed, PAD patients are exposed to complications that may lead to amputation and experience an increased incidence of cardiovascular events such as myocardial infarction, ischaemic stroke and cardiovascular death. Therefore, PAD can be considered a marker of systemic atherosclerosis and its early diagnosis might be useful in identifying patients at high cardiovascular risk. The evidence of a link between alcohol intake and PAD is modest if compared with that relative to coronary or cerebrovascular disorders (see above). Among the studies that took such a possible association into consideration, both the Strong Heart Study [36] and the Rotterdam Study [37] reported an inverse association between moderate alcohol use and PAD diagnosis (based on reduced Winsor indices). Such an association appears to be stronger in women than in men, even though another study reported the converse [38]. A subsequent sub-analysis of one of the two studies mentioned above, which examined PAD progression, recorded an inverse association between alcohol consumption and variation at 5 years of the Winsor index [39].

Two prospective studies evaluated the association between alcohol use and PAD risk in the general population. In an analysis from the Framingham Heart Study [40], which selected symptomatic PAD as the 'end' point, the authors reported a hazard ratio of 0.67 associated with a consumption of $13-24 \mathrm{~g} / \mathrm{d}$, that is, one to two drinks/d for men and of 0.44 associated with a consumption of 7-12 g/d, that is, one half to one drink/d for women. In the Physicians' Health Study, Camargo et al. [41] reported a hazard ratio of 0.74 associated with a consumption of seven or more drinks/week; the analysis, on the other hand, included only 66 PAD cases. In the latter study, alcohol use was associated with a $26 \%$ risk reduction of claudicatio intermittens. Another study, however, carried out in a diabetes mellitus cohort did not report any association between alcohol consumption and PAD [42]. Although PAD risk reduction was associated with preferential consumption of wine or beer in the Framingham Study [40], or with wine consumption in a sub-analysis of the Edinburgh Artery Study [38], the majority of studies failed to attribute the observed reduced risk of developing PAD to any particular alcoholic beverage.

Finally, a limited number of studies evaluated the association between moderate alcohol use and risk of developing abdominal aorta aneurysms (AAAs). An analysis of male smokers reported a ' $U$ '-shaped association curve between alcohol intake and AAA risk, with RR reductions ranging from
0.74 for consumptions up to $15 \mathrm{~g} / \mathrm{d}$ to 0.60 for intakes up to $30 \mathrm{~g} / \mathrm{d}$ and increased risk for higher intakes [43].

In summary, the association between moderate alcohol consumption and extra-coronary CVD is complex and heterogeneous. In particular, epidemiological studies confirm that PAD risk is reduced by moderate alcohol intake, that is, in the one to two drinks/d range. However, larger prospective studies are necessary to more precisely define the association between alcohol use and peripheral vascular disorders and to formulate recommendations.

\section{Alcohol and cardiovascular risk factors}

\section{Lipid profile}

An early review, published in 1999 [44], suggested that moderate alcohol use is associated with increased plasma concentrations of high-density lipoprotein (HDL) cholesterol $(\mathrm{HDL}-\mathrm{c})$, with a clear dose-response relationship, namely, an increase of $0.133 \mathrm{mg} / \mathrm{dl}$ for every gram of alcohol ingested daily. Likewise, every gram of alcohol was associated with a $0.294 \mathrm{mg} / \mathrm{dl}$ increase in plasma apolipoprotein A-I levels (Apo-Al; the foremost component of HDL) and of $0.190 \mathrm{mg} / \mathrm{dl}$ in triacylglycerol (TG) plasma levels. Total cholesterolaemia was not influenced by alcohol intake, while TG increase was more obvious in the post-prandial phase.

Alcohol consumption would induce increased hepatic synthesis of Apo-Al, Apo-All and of HDL-C and its subfractions $\mathrm{HDL}_{1}, \mathrm{HDL}_{2}$ and, notably, $\mathrm{HDL}_{3}$ via increased activity of lipoprotein lipase (LPL) [45]. Alcohol might also influence the activity of other key metabolic enzymes such as lecithin:cholesterol acyl-transferase (LCAT) and cholesterol-ester-transfer protein (CETP). In particular, alcohol increases LCAT activity while decreasing CETP, in turn increasing HDL-C concentrations and reverse cholesterol transport [46].

It remains however to be established whether alcoholinduced increase of $\mathrm{HDL}-\mathrm{C}$ concentrations would entirely explain its cardioprotective properties. Indeed, on the one hand intervention studies failed to show that increasing HDL-c lowers cardiovascular mortality [47]; on the other, HDL exerts a number of cardioprotective actions including reduced low-density lipoprotein (LDL) oxidation, inhibition of inflammatory molecules migration into the subendothelial space and reverse cholesterol transport [48].

In summary, moderate alcohol use dose-dependently increases HDL-C and Apo-Al (see also a recent meta-analysis by Brien et al.[49]). Conversely, no significant alterations of total and LDL-C are observed. Increased TGs usually occur after the ingestion of $>60 \mathrm{~g} / \mathrm{d}$, that is, five drinks/d of alcohol only. These overall favourable effects might contribute to the reduction of cardiovascular risk observed in moderate alcohol drinkers.

\section{Blood pressure}

The effects of alcohol on blood pressure are manifold. Only modest intakes appear to be healthful; usually, a linear association between alcohol intake and increased blood pressure is reported in both normal subjects and 
hypertensive patients [50,51]. The hypertensive effect of alcohol, in interventional studies, is yet reversible [51]

Several observational studies suggested that intake of alcohol in excess increases blood pressure [52]. Klatsky et al. evaluated blood-pressure changes as related to alcohol use in 83,947 men and women and concluded that those who consumed $>3$ drinks/d had higher systolic and diastolic pressure values as compared with teetotallers [53]. In 1995, Gillman et al. reported - in young adults - a ' $J$ '-shaped association between alcohol use and blood pressure, minimal values being noted in those who consumed one or two drinks/d [54]. A simple linear association was, in contrast, reported by others [55]. Compulsive drinkers exhibit higher risk for stroke in the early morning, which has been tentatively linked to a possible circadian effect of alcohol on blood pressure [56]. Consumption of several drinks in the evening appears to induce a moderate increase in daytime pressure but a reduction in the night-time one. The net effect is that of a mild overall increase, at least in Japanese subjects [57]. Normotensive subjects from the Women's Health Study and Physicians' Health Study cohorts have been examined to ascertain the risk of developing hypertension in relation with alcohol consumption. This analysis concerned 28,848 healthy women and 13,455 healthy men. The results show a decreased risk of incident hypertension in drinking women, but an increased risk in men as compared with abstainers. Consumption threshold, apparently, is four drinks a day for women vs. just one drink for men [58]. Some authors observed that acute alcohol ingestion was associated with a sudden drop in blood pressure (because of either direct or indirect vasodilatory effects), followed by an increase [59].

Genetic polymorphisms of enzymes that metabolise alcohol, for example aldehyde dehydroxygenase, might influence their effects on blood pressure [60].

The mechanism(s) by which ethanol influences blood pressure have not been clarified yet. While alcohol itself might stimulate the production of endothelin ET-1, whose urinary excretion is in fact increased by alcoholic beverages [51], red wine polyphenols might reduce its synthesis by inhibition of ET1 gene transcription [61]. Endothelial function might also augment after red wine ingestion [62-64], possibly independent from an effect of alcohol per se [63]. However, ad-hoc clinical studies measuring flow-mediated dilation yielded mixed results [65].

In summary, available data suggest that alcohol in very moderate amounts appears to exert neutral or beneficial effects on blood pressure and that red wine might be superior to other alcoholic beverages [24,66,67]. Because moderate alcohol use is being associated with better cardiovascular prognosis in hypertensive patients, consumption levels of $<30 \mathrm{~g} / \mathrm{d}$, that is $2.5 \mathrm{drinks} / \mathrm{d}$ for men and $<15 \mathrm{~g} / \mathrm{d}$, that is $\sim$ one drink/d for women, though hypertensive, might be advantageous over abstention [57].

\section{Inflammation and circulating surrogate markers of CVD}

Several epidemiological studies reported an association between moderate alcohol intake and low plasma concentrations of inflammation markers (Table 1). A study carried
Table 1 Effects of moderate alcohol consumption on the main markers of inflammation and on hemostasis factors in epidemiological and intervention studies.

\begin{tabular}{lll}
\hline & $\begin{array}{l}\text { Epidemiological } \\
\text { studies }\end{array}$ & $\begin{array}{l}\text { Intervention } \\
\text { studies }\end{array}$ \\
\hline C-reactive protein (CRP) & +++ & $+/-$ \\
Interleukin-6 (IL-6) & + & $+/-$ \\
Tumour necrosis factor- $\alpha$ & $+/-$ & $+/-$ \\
$\quad$ (TNF- $\alpha$ ) & & +++ \\
Fibrinogen & ++ & $+/-$ \\
Plasminogen activator & $+/-$ & $+/-$ \\
$\quad$ inhibitor-1 (PAI-1) & & \\
Tissue plasminogen & $+/-$ & ++ \\
$\quad$ activator (TPA) & + & \\
Adiponectin & + & \\
\hline Effects: + I- uncertain; & + modest; ++ strong; +++ very \\
strong. &
\end{tabular}

out on two large cohorts, that is men from the Health Professionals Follow-up Study, HPFS, and women from the Nurses' Health Study II, NHSII, reported that, in comparison to abstainers, $15-30 \mathrm{~g} / \mathrm{d}$ alcohol consumption was associated with a reduction in serum concentrations of C-reactive protein (CRP), interleukin 6 (IL-6) and the soluble tumour necrosis factor-alpha (TNF-alpha) receptors, sTNF-R1 and sTNF-R2 [68]. Men who consumed one or two drinks/d had 26\% CRP and 36\% IL-6 lower concentrations than teetotallers. Women exhibited a similar trend at half of the intake levels of men [68]. Similar results have also been reported by Imhof et al. [69], who showed a 'U'shaped relationship between serum CRP concentration and alcohol intake. In particular, lower serum CRP levels were observed at 20-40 g/d alcohol intake, while higher concentrations were found at $\geq 80 \mathrm{~g} / \mathrm{d}$ alcohol intake [69]. The purported anti-inflammatory effect of alcohol intake up to $40 \mathrm{~g} / \mathrm{d}$ has been confirmed in many European populations, in which lower serum fibrinogen and leucocyte concentrations and decreased haematic viscosity have been found to be associated with reduced CRP levels in moderate drinkers, regardless of the kind of drink [70]. Other studies, for example the Health, Aging and Body Composition Study, investigated the association between IL-6 and alcohol consumption, thus highlighting a 'J'-shaped curve, with the nadir placed at one-to-seven drinks/week [71]. A similar pattern has also been observed for CRP, but not for TNF-alpha and plasminogen activator inhibitor-1 (PAI-1). In addition in diabetic patients, moderate alcohol intake is associated with lower serum concentrations of fibrinogen, sTNF-R2 and soluble vascular adhesion molecule-1 (sVCAM-1) as well as higher levels of adiponectin [72].

Although methodological differences in alcohol-intake assessment impair conclusive results, the overall body of evidence seems to suggest an anti-inflammatory effect of restrained alcohol consumption. However, the ' $J$ '- and ' $U$ 'shaped curves mentioned above are indicative of a threshold value over which alcohol intake may have a proinflammatory effect.

The few intervention studies that investigated the effects of moderate alcohol consumption on circulating 
concentrations of PCR, IL-6, TNF-alpha, PAI-1 and tissue plasminogen activator (TPA) yielded conflicting results (Table 1). A recent meta-analysis showed that low alcohol intake reduces serum concentrations of PCR, IL- 6 and TNFalpha, although to a non-significant extent [49]. This metaanalysis only included five studies on CRP, three on TNFalpha and two on IL-6. Conversely, alcohol consumption significantly increases adiponectin (four studies) and decreases fibrinogen (seven studies) by an average of $0.20 \mathrm{~g} / \mathrm{l}$, which might contribute to its hypothesised cardio-protective effects [73]. As far as adiponectin is concerned, the effects of alcohol are unclear and data are scant. Moderate alcohol consumption increases adiponectin concentrations by $0.6 \mathrm{mg} / \mathrm{L}$ on average [74], that is, an increase similar to that produced by the powerful insulin-sensitisers thiazolinediones [75].

The effects of alcohol on other haemostatic parameters such as plasminogen, thromboxane, von Willebrand's factor and E-selectin as well as those on endothelial markers, for example intracellular adhesion molecule 1 (ICAM) and VCAM are still unclear as data are insufficient and conflicting.

\section{Metabolic effects of alcohol}

\section{Metabolic syndrome}

The metabolic syndrome (MS) is a multifactorial disorder that, according to the recent International Diabetes Federation definition, requires the presence of central obesity and at least two of the four following abnormalities: high TGs, low HDL-C, high blood pressure or raised fasting plasma glucose level. According to the Adult Treatment Panel-III (ATP-III) definition (with which the general practitioner is more familiar), the presence of any three of the five risk factors mentioned above allows to diagnose the MS [76].

The relation between alcohol intake and MS prevalence is controversial, as alcohol has positive effects on some of its factors, for example HDL-c serum concentrations and negative effects on other ones, for example blood pressure levels [77].

Observational studies from different geographic areas report reduced MS prevalence in moderate drinkers and an increase of MS prevalence in abstainers, heavy drinkers and those who started to drink early in their lives. Therefore the relation between alcohol consumption and MS risk is ' $\mathrm{J}$ '- or 'U'-shaped. Freiberg et al. [78] observed in low-to-moderate drinkers a reduced MS prevalence of $48 \%$ in men and $47 \%$ in women younger than 50, regardless of ethnic origin, in comparison to abstainers. This study, which individually evaluated separately the various components of the MS, suggested that moderate alcohol consumption was associated with reduced prevalence of low serum concentration of HDL-c, high levels of TG and higher waist circumference, as well as hyperinsulinaemia [78]. This association was stronger in consumers of wine and beer, while liquor drinkers showed only a favourable association with HDL-c levels. However, other studies do not confirm the positive association between moderate alcohol consumption and MS risk. For instance, a study carried out in Italy, performed on subjects between 65 and 84 years of age, reported that moderate alcohol intake significantly worsened, in men but not in women, three out of the five components of MS, that is systolic blood pressure, glycaemia and waist circumference, suggesting a sex effect of ethanol [79].

Indeed, a recent meta-analysis that also took into account sex, showed that ethanol intake of $<40 \mathrm{~g} / \mathrm{d}$, that is $\sim 3.5$ drinks/d in men and $<20 \mathrm{~g} / \mathrm{d}$, that is $\sim$ two drinks/ d in women reduces the risk of MS by $16 \%$ and $25 \%$, respectively, as compared with abstainers (Table 2) [80].

\section{Alcohol and insulin sensitivity}

The beneficial effects of moderate alcohol consumption on the MS and some of its components have been attributed to an amelioration of insulin sensitivity, partly mediated by lower visceral adiposity. This effect, observed in several epidemiological studies, has not been conclusively confirmed by intervention studies that, being devoid of confounders, are the most suitable for clarifying potential mechanisms of action.

In observational studies, alcohol consumption of $10-30 \mathrm{~g} /$ $\mathrm{d}$, that is $\sim$ one or two drinks/d is associated with lower fasting insulin concentrations and lower markers of insulin resistance, under both fasting and glucose load conditions $[81,82]$. In particular, the Normative Aging Study [81] showed that the relation between alcohol intake and insulin sensitivity markers is not linear, as consumers of one to two drinks/d were less insulin-resistant than subjects who consumed either less or more than this amount. On the contrary, no association between alcohol, insulin sensitivity (as evaluated by euglycaemic clamp) and insulin secretion was reported by the Uppsala Longitudinal Study of Adult Men

Table 2 Relative risk of metabolic syndrome as related to the habitual alcohol consumption of men and women: a metaanalysis of seven observational studies.

\begin{tabular}{llll}
\hline Alcohol & Category 1 & Category 2 & Category 3 \\
consumption & $0-39.9 \mathrm{~g} / \mathrm{d}$ & $40-59.9 \mathrm{~g} / \mathrm{d}$ & $>60 \mathrm{~g} / \mathrm{d}$ \\
Men & RR $(95 \% \mathrm{Cl}): 0.84(0.75,0.94)$ & RR $(95 \% \mathrm{Cl}): 0.95(0.83,1.09)$ & $\mathrm{OR}(95 \% \mathrm{Cl}): 0.99(0.71,1.38)$ \\
& $P=0.004$ & $P=0.49$ & $P=0.94$ \\
Women & Category 1 & Category 2 & \\
& $0-19.9 \mathrm{~g} / \mathrm{d}$ & $20-39.9 \mathrm{~g} / \mathrm{d}$ & - \\
& RR $(95 \% \mathrm{Cl}): 0.75(0.64,0.89)$ & RR $(95 \% \mathrm{Cl}): 0.81(0.57,1.14)$ & \\
& $P=0.0007$ & $P=0.22$ & \\
\hline
\end{tabular}

RR, Relative Risk; $\mathrm{Cl}$, Confidence Interval. Modified from Alkerwi A et al. [80]. Note that consumption levels used for computation are different between men and women. 
[83]. An inverse relation between moderate alcohol consumption and insulin resistance has been reported in normalweight subjects, but not in overweight/obese patients with a Homeostasis Model of Assessment (HOMA) index $<2$ [84].

The few available intervention studies provide controversial results. However, the majority of them indicates that $25-39 \mathrm{~g} /$ $\mathrm{d}$ ethanol consumption, that is $\sim$ two or three drinks/d improves lipid profile and insulin sensitivity as well as serum adiponectin in menopausal women $[85,86]$, while in men it seems to have no influence on insulin sensitivity and fat distribution and, indeed, it may promote hepatic steatosis [74,87].

In summary, epidemiological data support a reduction of MS risk associated with low-to-moderate alcohol consumption. This effect is particularly evident for some of the MS components such as HDL-c and fasting insulin levels. However, due to the limited sample size and short duration (3-8 weeks), the few intervention studies do not allow ascertaining the role of ethanol intake on insulin sensitivity.

\section{Alcohol, overweight and obesity}

The addition of alcohol to a normocaloric diet should increase body weight because of the added calories. Moreover, alcohol increases appetite (due to its hypoglycaemic action) and facilitates socialisation, in turn increasing food intake [88]. However, observational studies failed to correlate alcohol use with body weight. In an American women cohort, Wannamethee et al. [89] observed that the lowest body mass index (BMI) values were associated with alcohol intakes of 5-30 g/d; in a 13year follow-up, moderate alcohol use was also associated with lower chance to gain weight or to become overweight or obese [90]. Likewise, the National Health and Nutrition Examination Survey (NNAHES) cohort exhibited a clear inverse association between moderate alcohol intake and obesity risk (and, to a lower extent, overweight risk) [91]. In particular, total and abdominal adipose tissue in moderate drinkers is reportedly less than that in abstainers or heavy drinkers [92], even if an intervention study on 35-70year-old men failed to observe any variation of abdominal fat following the consumption of $40 \mathrm{~g} \mathrm{~d}^{-1}$ for 4 weeks [74].

In summary, the association between alcohol use and body weight is multifaceted and difficult to correctly compute, mostly because of the many confounding factors that hamper its correct assessment. However, while elevated alcohol intake is associated with increased risk of obesity or overweight, moderate consumption appears to have neutral or favourable effects [93].

\section{Alcohol and diabetes}

Alcohol consumption has always been considered a risk factor for diabetes mellitus. However, recent publications suggest that moderate alcohol use might actually be associated with reduced incidence of type 2 diabetes mellitus (T2DM) and its vascular complications.

A meta-analysis by Koppes et al., which analysed 15 studies on 369,862 patients followed up for an average of 12 years, concluded that subjects who consumed $6-48 \mathrm{~g} / \mathrm{d}$, that is onehalf to four drinks/d of ethanol exhibited a $30 \%$ reduced risk of
T2DM as compared with teetotallers or consumers of $>48 \mathrm{~g} /$ $d$ of ethanol [94]. This effect is independent of either sex or BMI. In addition, a lower incidence of T2DM was observed in women with moderate alcohol intake (but not in men) when compared with abstainers in a prospective study by Hodge et al. [95] Moderate alcohol use and reduction of cardiovascular risk in diabetic patients are also associated [96].

Moderate alcohol consumption and cardiovascular risk in diabetics have also been found to be inversely associated in the Second Manifestations of ARTerial (SMART) disease study [97]: moderate (10-20 drinks/week) ethanol use was associated with reduced risk of acute coronary disease and stroke (hazard ratio (HR) 0.39; confidence interval $(\mathrm{Cl})$ : $0.20-0.76)$ as well as lower overall mortality (HR $0.40 ; \mathrm{Cl}$ 0.24-0.69), when compared with abstainers. This association was also apparent when red wine was highlighted.

Recently, Djousse et al. [98], based on the results of an investigation on 28,345 women, concluded that the positive association between moderate alcohol use and cardiovascular risk reduction can be partly explained by the beneficial effects of ethanol on glucose metabolism, in addition to lipid profile, inflammation and blood pressure.

Current guidelines addressed to diabetic patients are rather cautious because of the calories and body-weight issues, in addition to some untoward metabolic and vascular effects of alcohol. In brief, such guidelines indicate that if a diabetic adult chooses to drink alcohol, his/ her daily intake should be kept constantly modest (10-13 g, i.e., one drink or less for women and 20-25 g, i.e., two drinks/d or less for men). To reduce the risk of nocturnal hypoglycaemia in patients on insulin or insulin secretagogues, alcohol should be ingested with food [99].

\section{Moderate alcohol use and liver disease}

Alcoholic liver disease (ALD) is the most prevalent cause of advanced liver disease in the Western world. It comprises a large spectrum of liver injuries, ranging from fatty liver or simple steatosis (alcoholic fatty liver disease, AFLD) to acute alcoholic hepatitis, alcoholic steatohepatitis (ASH), chronic hepatitis with hepatic fibrosis and cirrhosis $[100,101]$. Non-alcoholic fatty liver disease (NAFLD), on the other hand, is the most common liver disorder in Western countries and affects as many as $25-30 \%$ of adults. NAFLD might shortly become the most common liver disease worldwide [102].

The distinction between NAFLD and AFLD or between NASH (non-alcoholic steatohepatitis) and ASH is based on average daily alcohol consumption, the discriminating threshold being $20-30 \mathrm{~g} / \mathrm{d}$ [102] by international standards. Therefore, proper diagnosis is based on daily alcohol-intake determination. In clinical practise, this is usually done by estimating the 'drinks per day' consumption (see above in this paper for the definition of drink units) [103].

In the general population, the daily threshold of alcohol intake associated with an increased risk of liver injury is between one and two drinks per day for women and two and three drinks per day for men. Certainly, drinkers of more than $30-50 \mathrm{~g} / \mathrm{d}$ of alcohol for more than 5-10years are exposed to a significant risk to develop ALD. Not all these drinkers, however, develop a liver disease. Indeed, we know that some 
host- and environment-related predisposing factors promote ALD development [100,101]. For example, genetic polymorphisms of alcohol dehydrogenase and their interaction with genes involved in the generation and scavenging of free radicals influence susceptibility to ALD [100]. Obesity, diabetes, insulin resistance, metabolic syndrome (including NAFLD) as well as hepatitis $\mathrm{C}$ virus ( $\mathrm{HCV}$ ) infection increase the liver-damaging effects of alcohol $[100,101]$.

Current belief is that low or moderate alcohol consumption should be forbidden in patients with liver disease. Therefore, subjects with chronic liver disease (regardless of its aetiology), are usually warned by clinicians to avoid any kind of alcoholic beverage. Conversely, whether moderate, that is less than one to two units per day, that is $20-30 \mathrm{~g} / \mathrm{d}$ daily alcohol intake could be safe in patients with NAFLD remains an open issue.

Only $4-5 \%$ of patients with NAFLD, namely those exhibiting a more severe subtype known as steatohepatitis (NASH, which is characterised by inflammatory infiltrates, ballooning hepatocellular injury and fibrosis) are at a high risk for cirrhosisand hepatocellular carcinoma (HCC)-related mortality. We also know that most non-cirrhotic NAFLD patients who are moderate drinkers are not at significant risk of worsening their liver disease [104-107]. Patients with NAFLD and, especially, those with NASH, are - conversely - at increased risk for cardiovascular or coronary-heart disease (CVD or CHD). Indeed, they are twice more likely to die from CVD than from liver diseases [108]. Evaluation of cardiovascular risk and management of $\mathrm{CHD}$ risk factors is, therefore, mandatory in these patients.

As moderate alcohol use not only is associated with reduced CHD morbidity and mortality risk, but also improves metabolic risk factors related to both CVD and NAFLD $[85,109]$ and seems to partially protect from NASH and NAFLD [106,107], patients with NAFLD who drink no more than two-three drinks per day could perhaps be allowed to continue their drinking habits. This issue is, however, still unresolved [110].

\section{Alcohol, cognitive impairment and dementia}

Five epidemiological studies have been published on the association between alcohol use and incidence of dementia and Alzheimer's disease [111-115]. In addition, two metaanalyses examined 26 and 15 studies, respectively $[116,117]$.

The available evidence comes mostly from longitudinal cohort studies, in which non-dement or mild cognitive impairment $(\mathrm{MCl})$ elderly have been followed to monitor their cognitive performance. The results are summarised in Table 3.

All studies revealed a reduction of dementias and Alzheimer's risk associated with moderate alcohol use, as compared with abstainers. The extent of risk reduction greatly varies among studies and meta-analyses. All studies reported a negative association between alcohol intake and risk of dementia; publication bias is unlikely, but cannot be ruled out. Alcohol would decrease cerebrovascular risk via one or more mechanisms described above, such as its antiinflammatory effect [118]. This is supported by a recent study showing that ethanol is able to reduce the synaptic damage induced by beta-amyloid and synuclein [119]. One should not forget however that alcohol in excess causes at least two well-known neurological diseases characterised by cognitive decline and dementia, that is Wernicke-Korsakoff's and Marchiafava-Bignami's syndromes, and that an alcohol-mediated form of dementia has been described, which is accompanied by cerebral atrophy and a typical alteration of white and grey matters.

\section{Alcohol, skeletal frailty and osteoporosis}

Several observational studies indicate that alcohol consumption might influence bone density, depending on intake levels. In general, moderate alcohol use has no significant influence on bone density (or it has even positive effects), whereas data on heavy intake are conflicting, mainly pointing to negative effects on bone structure.

The effects of two or three drinks/d depend on age, sex and hormonal profile; for example positive effects are described for menopausal, but not for fertile women. The type of alcoholic beverage might also be important, as favourable effects have also been reported separately for wine [120] and beer [121]. These observations might be explained by the non-alcoholic content of either beverage. In a human study [122], consumption of two drinks/ d increased bone density, while more than two glasses/ d exerted detrimental effects on both spine and femur. Finally, in a study carried out in twins with different alcohol use, moderate consumption was associated with higher bone mass [123]. A very recent and large study in postmenopausal women observed that the association between moderate consumption and higher bone mass cannot be explained by lifestyle, hence suggesting some direct effect of ethanol [121].

As far as mechanisms of action are concerned, alcohol has been suggested to slow bone resorption with no effects on bone formation; in turn, the net consequence on mass would be positive [124]. This hypothesis is partly confirmed by the observation that low-to-moderate alcohol use, that is $<27$ drinks/week for men and $<13$ drinks/ week for women has not been associated with any increased fracture risk $[125,126]$.

One note of caution concerns the deleterious effects of high alcohol intake. Indeed, excessive and prolonged alcohol consumption lowers bone density and is considered a major risk factor for bone fractures $[125,127]$.

\section{Alcohol and cancer}

Most cancers are reportedly not associated with moderate alcohol intake. Only the association between light alcohol consumption and cancer risk for sites for which sufficient or limited evidence for carcinogenicity of alcohol is available $[128,129]$, that is, cancers of the upper digestive and respiratory tract (oral and pharyngeal cancer, oesophageal squamous cell carcinoma and laryngeal cancer), colorectum, pancreas and breast will be examined in this paper. Adenocarcinoma of the oesophagus will not examined because this neoplasm is not to be associated to alcohol drinking [130].

A positive association between alcohol and liver cancer has been established [128]. However, the latter will not 


\begin{tabular}{|c|c|c|c|c|}
\hline Title & $\begin{array}{l}\text { Characteristics and } \\
\text { No. participants }\end{array}$ & Outcome (cases) & Alcohol consumption & Relative risk estimate $(95 \% \mathrm{Cl})$ \\
\hline $\begin{array}{l}\text { Alcohol consumption and risk } \\
\text { of dementia: the Rotterdam } \\
\text { Study [111]. }\end{array}$ & $\begin{array}{l}\text { Cohort population study on } 7893 \\
\text { non-demented subjects }\end{array}$ & Dementia (197) AD (146) & 1-3 drinks/d vs. nondrinkers & $0.58(0.38-0.90)$ \\
\hline $\begin{array}{l}\text { Alcohol consumption and cognitive } \\
\text { function in late life: a longitudinal } \\
\text { community study [113]. }\end{array}$ & $\begin{array}{l}\text { Cohort study on } 1098 \text { non- } \\
\text { demented elderlies }\end{array}$ & $\begin{array}{l}\text { Reduction cognitive } \\
\text { test or neurocognitive } \\
\text { tests }\end{array}$ & $\begin{array}{l}\text { Minimal and moderate drinker } \\
\text { vs. nondrinker }\end{array}$ & $\begin{array}{l}\text { For any increase of one SD in the } \\
\text { reduction of MMSE the risk of being } \\
\text { minimal drinker vs. that of an } \\
\text { abstainer was } 0.3(0.14-0.65) \text { and } \\
0.08(0.02-0.28) \text { that of moderate } \\
\text { drinkers }\end{array}$ \\
\hline $\begin{array}{l}\text { Alcohol intake and risk of } \\
\text { dementia [112] }\end{array}$ & $\begin{array}{l}\text { Cohort study on } 980 \text { non- } \\
\text { demented elderlies }\end{array}$ & Dementia (260) AD (199) & $\begin{array}{l}\text { Three vs. zero servings of } \\
\text { wine }\end{array}$ & $0.55(0.84-0.39)$ \\
\hline $\begin{array}{l}\text { Current alcohol consumption and } \\
\text { its relationship to incident } \\
\text { dementia [115] }\end{array}$ & $\begin{array}{l}\text { Cohort study on } 3202 \text { non- } \\
\text { demented elderlies ( } \geq 75 \text { years) }\end{array}$ & Dementia (217) AD (111) & $\begin{array}{l}\text { Any kind of alcohol intake vs. } \\
\text { no intake }\end{array}$ & $\begin{array}{l}0.71(0.53-0.96) \text { dementia } \\
0.58(0.38-0.89) \mathrm{AD}\end{array}$ \\
\hline $\begin{array}{l}\text { Alcohol consumption, mild cognitive } \\
\text { impairment, and progression to } \\
\text { dementia [114] }\end{array}$ & $\begin{array}{l}\text { Cohort study on } 121 \mathrm{MCl} \\
\text { subjects }\end{array}$ & Dementia (14) & $<1$ drink/d vs. no intake & $0.15(0.03-0.78)$ \\
\hline
\end{tabular}

AD, Alzheimer's disease; VAD, Vascular dementia; MCI, Mild cognitive impairment; MMSE, Mini Mental Status Examination; $\mathrm{Cl}$, Confidence Interval. 
be analysed here because of known problems in the interpretation of results from epidemiological, mainly case-control, studies. In fact, most alcohol-related liver cancers follow cirrhosis, which leads to a reduction of alcohol drinking and, thus, to a substantial underestimation of the real associations [131]. Therefore, quantification of risks for low-to-moderate alcohol consumption and liver cancer remains unresolved. Alcohol drinking might be inversely associated to kidney cancer and non-Hodgkin lymphoma [128]. These issues, however, will not be discussed here.

Establishing if there is or not any positive association between low doses of alcohol and some cancers known to be alcohol-related is particularly important [132], as it is still unclear whether there is an alcohol threshold below which alcohol drinking would not affect cancer development.

Figure 1 shows the main results for light alcohol drinking, defined as one or few drinks/d, from meta-analyses of studies on selected digestive tract and larynx cancers [133-137]. Summary data on light drinking and breast cancer risk were extracted from the collaborative reanalysis of 53 epidemiological studies of breast cancer [138] and from the Million Women Study [139].

For oral and pharyngeal cancer, two meta-analyses, based on 19 case-control studies and one cohort study, provided evidence that an increased risk is present also at low doses of alcohol consumption [136,140] (overall RR 1.21 (95\% Cl, 1.10-1.33) for one or few drinks/d vs. Non-/ occasional drinkers) [136]. The corresponding estimates were $1.17(95 \% \mathrm{Cl}, 1.01-1.35$, based on nine studies) for oral cavity and $1.23(95 \% \mathrm{Cl}, 0.87-1.73$, based on five studies) for pharyngeal cancers [140]. The sensitivity analyses provided no evidence for a substantial influence of studies reporting estimates unadjusted for smoking.

A meta-analysis of oesophageal squamous cell carcinoma reported an association with low doses of alcohol similar to that of oral and pharyngeal cancer [134]. The summary RRs for light drinking were $1.31(95 \% \mathrm{Cl}, 1.10-1.57)$ for the overall analysis, based on 26 studies and 1.35 ( $95 \% \mathrm{Cl}, 0.92-1.98)$ for cohort studies alone ( 8 studies). When the analysis was stratified by geographical area, the association was stronger in Asia $(\mathrm{RR}=1.63 ; 95 \% \mathrm{Cl}, 1.20-2.22)$ than in other regions of

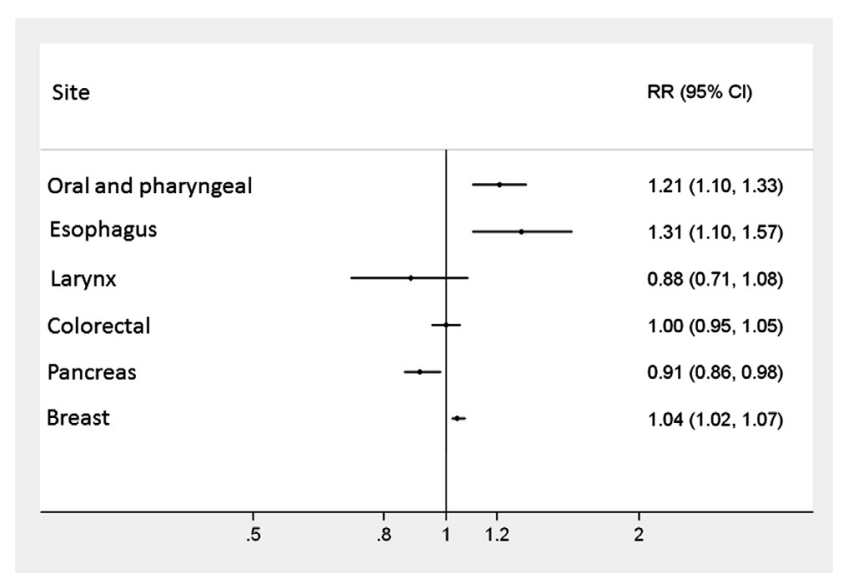

Figure 1 Moderate alcohol use and cancer risk in selected sites. RR, relative risk for alcohol intakes of $\leq 1 \mathrm{drink} / \mathrm{d}$, as compared with abstainers and occasional drinkers. the world $(\mathrm{RR}=1.17 ; 95 \% \mathrm{Cl}, 0.99-1.39)$, suggesting a potential effect modification by environmental or genetic susceptibility. No increase in risk by consumption of low doses of alcohol was observed in never-smokers $(\mathrm{RR}=0.74 ; 95 \% \mathrm{Cl}$, 0.47-1.16), but the estimate was based on five studies only.

By contrast, laryngeal cancer was not associated with alcohol consumption up to one drink/d [135]. The summary RR for light drinking, based on 10 case-control and two prospective studies, was $0.88(95 \% \mathrm{Cl}, 0.71-1.08)$. Results were unaffected by several subgroup analyses, including that adjusted for smoking.

Almost 50 studies provided information on low doses of alcohol and colorectal cancer risk [133]. No overall association was reported with either colorectal $(R R=1.00 ; 95 \%$ $\mathrm{Cl}, 0.95-1.05)$, or colon ( $\mathrm{RR}=0.96 ; 95 \% \mathrm{Cl}, 0.90-1.02)$ or rectal $(\mathrm{RR}=1.06 ; 95 \% \mathrm{Cl}, 0.98-1.14)$ cancers. Results were consistent across strata of sex, geographical area and various other covariates.

A meta-analysis on alcohol and pancreatic cancer found strong evidence supporting the lack of positive associations at low-to-moderate alcohol intakes defined as less than three drinks/d [137]. Seventeen case-control and seven cohort studies were included and the summary RR was $0.92(95 \% \mathrm{Cl}$, $0.86-0.97)$. The estimates were almost the same when case-control or prospective studies were considered separately. When the analyses were repeated comparing consumption of one or less drink/d to non-occasional drinkers, the odds ratio (OR) was 0.91 (95\% Cl, 0.86-0.98). Similarly, in the PanScan study [141], the pooled OR was, if anything, higher in nondrinkers $(\mathrm{OR}=1.19 ; 95 \% \mathrm{Cl}, 0.97-1.48)$ as compared with drinkers of less than $5 \mathrm{~g} \mathrm{~d}^{-1}$ of alcohol; also, there was no clear association up to consumption of $<30 \mathrm{~g} \mathrm{~d}^{-1}$.

In a collaborative meta-analysis on breast cancer [138], the RRs were $1.01(p>0.05)$ for women reporting alcohol consumption $<5 \mathrm{~g} / \mathrm{d}$ and $1.03(p>0.05)$ for those consuming $5-14 \mathrm{~g} / \mathrm{d}$, as compared with women who did not drink. The Million Women Study [139] found RRs of $1.00(p>0.05)$ for $\leq 2$ drinks/week, that is, $<3 \mathrm{~g} / \mathrm{d}$ of alcohol and $1.08(p<0.05)$ for 3-6 drinks/week, that is, around $4-8 \mathrm{~g} / \mathrm{d}$, compared with non-drinkers. Exclusive consumption of wine showed a similar risk pattern. Thus, results for breast cancer are not totally consistent, but indicate a small increase in risk even for light drinking, in the order of one drink/d. This finding may have different impact on women according to their menopausal state: indeed, in young women, especially those with familiar history of cancer, even a small increase of breast cancer risk by moderate alcohol consumption would be unacceptable because it would not be counterbalanced by a concomitant positive effect on a very low cardiovascular risk. In contrast, a small increase of breast cancer risk by moderate alcohol use in post-menopausal women would appear negligible with respect to the substantial reduction of a high cardiovascular risk.

In summary, moderate drinking of up to one drink/d leads to an increased risk of $20-30 \%$ of oral and pharyngeal cancer and of oesophageal squamous cell carcinoma, though these estimates remain open to discussion due to under-reporting. No significant association emerges with the risk of laryngeal, colorectal and pancreatic cancers. An increased risk of breast cancer appears at intakes of three to six drinks/week. A positive association between alcohol and liver cancer has been established, but no reliable quantification of the risks for low-to-moderate alcohol consumption is as yet possible. 
In terms of attributable fraction of cancers that would be eliminated by restricting alcohol consumption, about 390,000 (3.6\%) cancers and 230,000 (3.5\%) cancer deaths were attributed in 2002 to worldwide alcohol drinking [142]. These included over $5 \%$ of cancers and cancer deaths in men and about $1.5 \%$ of cancers and cancer deaths in women. Restriction of alcohol drinking to the limits indicated by the European Code Against Cancer [143] (20 g/d for men and $10 \mathrm{~g} / \mathrm{d}$ for women) would avoid about $90 \%$ of cancers and cancer deaths in men and over $50 \%$ of cancers in women, that is about $330 /$ 360,000 cancer cases and about 200/220,000 cancer deaths (Bagnardi et al., 2012). Avoidance or limitation of alcohol consumption to two drinks/d for men and one drink/d for women is, therefore, a global public-health priority.

\section{Alcohol and all-cause mortality}

The most objective way to evaluate the role of alcohol in health is to assess total mortality (i.e., for all causes) associated with its use. Infarction, risks and benefits are, in this manner, compared with the same epidemiological hard 'end' point.

The association between total mortality and alcohol consumption not only depends on quantities and drinking behaviour, but also on the distribution of causes of death in the population at study. Further to the first study that showed a 'J'-shaped association between alcohol use and all-cause mortality [144], a meta-analysis combined the results of 34 prospective studies and investigated the association between alcohol consumption and all-cause mortality in over 1 million apparently healthy subjects. The results indicate that alcohol intake up to $40 \mathrm{~g} / \mathrm{d}$ was inversely associated with reduction of all-cause mortality, a maximum effect being apparent at about $6 \mathrm{~g}$ of ethanol per day. More than 3-4 drinks/d, conversely, were associated with a progressive linear increase in overall mortality [3]. This meta-analysis also separately analysed men and women [3]; maximal theoretical protection was similar in both sexes (mean reduction $\sim 18 \%$, at about $6 \mathrm{~g} / \mathrm{d}$, i.e., half a drink/d). The 'reversion point', that is the dose of alcohol associated with the same mortality as that observed in the

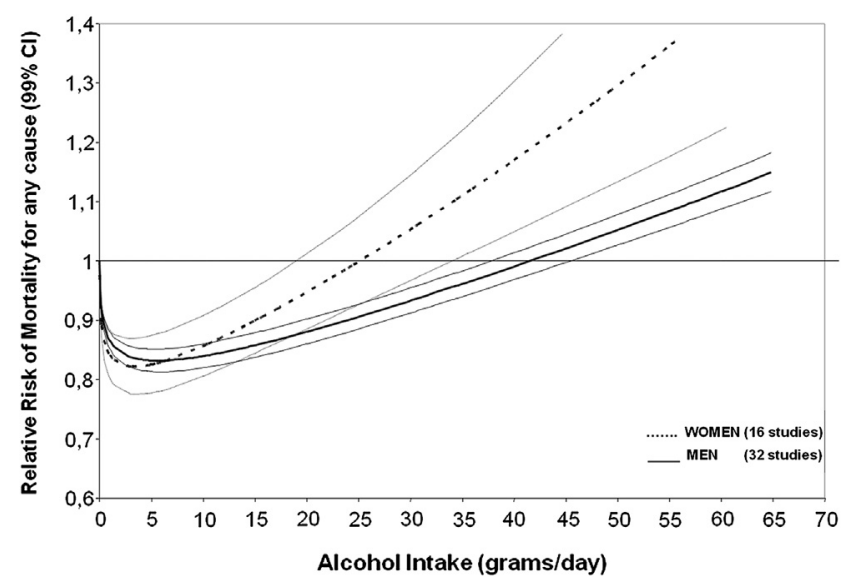

Figure 2 Relative risk of all-cause mortality and alcohol consumption in men and women. Data are from Di Castelnuovo et al. 2006 [3]. control group of abstainers, was reached at 1-1.5 drinks/ $\mathrm{d}$ in women and at about 3 drinks/d in men (Fig. 2). Clinical and biochemical data suggest that, indeed, women are more prone to the noxious effects of alcohol than men.

Another meta-analysis of seven prospective studies of 12,553 cardiovascular (acute myocardial infarction, stroke, or coronary disease) patients confirmed the risk reduction associated with moderate alcohol use, with a maximal significant decrease by $18 \%$ associated with $5-10 \mathrm{~g} / \mathrm{d}$ of ethanol, which is maintained up to $26 \mathrm{~g} / \mathrm{d}$ [12]. Even though we do not currently have enough data on secondary prevention in women, it is conceivable that their 'allowed' dose be similar to that of healthy women $[145,146]$. On the contrary, alcoholic patients with previous myocardial infarction exhibit a risk level for all-cause mortality that is double than that of regular and moderate drinkers [16]. Patients with CVD who drink $>3$ drinks/d should be warned of the risk of haemorrhage associated with alcohol abuse concomitant with acetylsalicylic-based drugs [145]

Also in the elderly, moderate alcohol use is associated with reduced all-cause death. In a study of 2000 subjects between 55 and 65 years of age at enrolment and followed up for an average of 20 years, total mortality was halved after 15 years - in moderate drinkers as compared with teetotallers [147].

Starting from the second half of the 1990s, several epidemiological studies have documented the existence of a 'J'-shaped curve that describes the association of alcohol use (and abuse) and total mortality. This curve also indicates a 'window' of consumption that might be incorporated into healthy lifestyles. Likewise, heavy drinking should be firmly discouraged.

\section{Differential health effects of the various alcoholic beverages}

Alcoholic beverages contain both ethanol and other components. The quality and quantity of the latter differs greatly between wine, beer and spirits, as well as within these categories (red vs. white wine, different beers, etc.). While the role of ethanol in human health has been elucidated to a great extent, that of the non-alcoholic components is less clear. Several experimental studies (in vitro and in animals) suggest that these components (in particular, polyphenols) might play important protective roles in human health $[148,149]$. Therefore, it has been hypothesised that polyphenol-rich alcoholic beverages such as red wine might be superior, in terms of healthy effects, to polyphenol-poor beverages. Particular attention has been paid to resveratrol, to which several of the alleged healthy effects of wine have been attributed, even though no human data are available [150]. Indeed, red wine contains not only resveratrol but phenols, tannins and flavonoids such as catechins and quercetin [151]. Some experimental evidence suggests that these components are endowed with healthful characteristics [152], such as antioxidant, anti-thrombotic and anti-inflammatory properties. As plaque formation is partially due to the oxidation of LDL within the arterial wall, polyphenols might retard this process and reduce atheroma formation [153]. Polyphenols such as resveratrol and quercetin inhibit platelet function and 
tissue factor, in turn reducing plaque formation. These effects are independent of the intake of anti-platelet drugs such as aspirin [154]. In vitro, resveratrol interferes with the formation of inflammatory mediators by leucocytes, reduces thrombogenicity linked to adhesion molecules and prevents thrombosis in animals via nitric oxide formation [155]. Wine consumption too has been associated with decreased concentrations of inflammatory markers such as CRP and higher levels of long-chain omega- 3 fatty acids [156]. Notably, red wine is the alcoholic beverage richest in polyphenols (though it contains resveratrol only in small amounts), but beer and some spirits also contain marked quantities of these compounds [150]. Indeed, polyphenols from wine and beer have been suggested to positively affect CVD, diabetes, some cancers, cognitive decline, Alzheimer's disease and respiratory tract disorders $[150,157]$.

Even though data from basic research consistently suggest favourable biological effects of polyphenols, epidemiological evidence in support of these effects in humans is scant $[4,150,157,158]$. As an example, the potential differences between wine and beer, as far as cardiovascular pathology and total mortality are concerned, have been recently compared by a meta-analysis that involved over 280,000 subjects [159]. The conclusion indicates that the effects of wine and beer do not differ significantly, reiterating the hypothesis that ethanol plays a major cardioprotective role [159] regardless of the polyphenolic content of the various beverages. No comparative data on wine vs. beer and spirits are available on total mortality, nor do we have enough evidence to say that red wine exerts effects different from that of white wine $[24,159]$. Concerning other pathological conditions, epidemiological data comparing wine and beer are scant and inconclusive $[4,150,157,158]$. Some authors believe that the type of alcoholic beverage determining the strongest event reduction in a particular country is the one most consumed locally [160].

In conclusion, the hypothesis that the antioxidant and antiinflammatory properties of non-alcoholic components might determine health effects different from that of ethanol is intriguing, but - at present - only suggested by laboratory data but not by conclusive epidemiological evidence.

\section{Conclusions}

Dozens of epidemiological studies and the meta-analyses that analysed their results clearly show a statistically significant association between moderate alcohol consumption, that is two or three drinks/d or 24-36 g of ethanol/d for men and one to two drinks/d or $12-24 \mathrm{~g}$ of ethanol/d for women and risk reduction of specific clinical events, namely those involving the cardio-circulatory system such as atherosclerosis, myocardial infarction or ischaemic (though not haemorrhagic) stroke. This association - which concerns both primary and secondary prevention - appears to be largely independent of confounding factors, as the inclusion of 'sick quitters' in the control groups of abstainers or the socioeconomic status of the cohorts. In population studies, the incidence of other common pathological conditions such as T2DM, dementia and osteoporosis also appears to be positively influenced by moderate alcohol use.

Moderate alcohol use appears on the other hand to be associated with modest but significant increased risk of cancers of the upper respiratory and gastrointestinal tracts, as well as of breast cancer.

The association between ethanol intake and all-cause mortality - which computes the overall effects on different diseases - follows the well-known 'J'-shaped curve: mortality among moderate drinkers is significantly lower than that of teetotallers and that of heavy drinkers. The nadir of this curve is located at consumption levels of approximately one drink/ $\mathrm{d}$; the mortality rate reverts to the levels of abstainers at consumption of $40 \mathrm{~g} / \mathrm{d}$ in men and $20-25 \mathrm{~g} / \mathrm{d}$ in women. Above these levels, overall mortality exceeds that of teetotallers.

The available data, namely the time sequence between exposure and effects, the dose-response association and the biological plausibility of the effects, suggest that the observed effects of alcohol are likely to be causal. In particular, moderate alcohol use favourably influences known risk factors for CVD such as plasma levels of HDL-c, fibrinogen, CRP, etc. These systemic effects might indeed explain the association between intake levels and cardiovascular risk reduction. Available data strongly suggest that it is ethanol rather that some other non-alcoholic component that exerts the proposed protective effects, even though an additive effect of, for example, polyphenols cannot be ruled out and is plausible. Moreover, the protective effects of alcohol only appear if its consumption is moderate and regular over time. Binge drinking, for example on limited occasions such as the weekends, is not associated with any positive effect and should be strongly discouraged. This caveat also applies to those who need to drive automobiles or use dangerous equipment.

The bulk of available data allows proposing some suggestions and guidelines, addressed to physicians and health professionals:

1) In adults and in the elderly (regardless of sex), spontaneous consumption of alcoholic beverages within $30 \mathrm{~g}$ ethanol/d, that is $\sim$ two drinks/d for men and $15 \mathrm{~g} / \mathrm{d}$, that is one drink/d for women are to be considered acceptable and do not deserve intervention by the primary care physician or the health professional in charge. In fact, there is no evidence to suggest complete abstention from alcohol drinking by moderate users.

2) Patients with increased risk for specific diseases, for example women with familiar history of breast cancer, or subjects with familiar history of early CVD or cardiovascular patients should discuss their drinking habits with their physician.

3) No abstainer should be advised to drink for health reasons.

4) Alcohol use must be discouraged in specific physiological or personal situations or in selected age classes (children and adolescents, pregnant and lactating women and recovering alcoholics). Moreover, the possible interactions between alcohol and acute or chronic drug use must be discussed with the primary care physician.

Disclosure to the lay public of the available notions between moderate alcohol use and health is debated and calls for caution. We propose that experts accurately communicate the health benefits and risks of alcohol consumption to the media and to the public, based on our current understanding and available evidence. In particular, the ' $J$ '-curve, demonstrating potential health benefits of low-to-moderate alcohol consumption and increased risk for degenerative disease (mainly beginning at the fourth decade of life) 
associated with abstinence or excessive consumption, including the concentrated use of alcohol over short periods (binge drinking), needs to be judiciously and carefully explained.

The choice to consume alcohol should be based on individual considerations, taking into account the influence on health and diet, the risk of alcoholism and abuse, the effect on behaviour and other factors that may vary with age and lifestyle.

Moderation in drinking and development of an associated lifestyle culture should be fostered.

\section{Appendix 1. Scientific societies that have agreed to sign the consensus paper}

ADI (Associazione Italiana di Dietetica e Nutrizione Clinica)
AMD (Associazione Medici Diabetologia)
ANMCO (Associazione Nazionale Medici Cardiologi
Ospedalieri)
CNR-ITB (Istituto di Tecnologie Biomediche del Centro
Nazionale della Ricerca)
FADOI (Italian Federation of the Associations of Internal
Medicine Physicians)
FIMMG (Federazione Italiana Medici Medicina Generale)
NFI (Nutrition Foundation of Italy)
SIC (Società Italiana di Cardiologia)
SID (Italian Society of Diabetology)
SIIA (Società Italiana dell'Ipertensione Arteriosa)
SIMG (Società Italiana di Medicina Italiana)
SIMI (Società Italiana Medicina Interna)
SIO (Società Italiana dell'Obesità)
SIOMMMS (Società Italiana dell'Osteoporosi del Metabolismo
Minerale e delle Malattie dello Scheletro)
SIPREC (Società Italiana per la Prevenzione Cardiovascolare)
SISA (Società Italiana per lo Studio della Arteriosclerosi)
SITECS (Società Italiana Terapia Clinica e Sperimentale)
SNAMID (Società Nazionale di Aggiornamento per il Medico
di Medicina Generale)
The Italian Stroke Forum

\section{References}

[1] Dawson DA. Methodological issues in measuring alcohol use. Alcohol Res Health 2003;27:18-29.

[2] Bagnardi V, Zatonski W, Scotti L, La Vecchia C, Corrao G. Does drinking pattern modify the effect of alcohol on the risk of coronary heart disease? Evidence from a meta-analysis. J Epidemiol Community Health 2008;62:615-9.

[3] Di Castelnuovo A, Costanzo S, Bagnardi V, Donati MB, lacoviello L, de Gaetano G. Alcohol dosing and total mortality in men and women: an updated meta-analysis of 34 prospective studies. Arch Intern Med 2006;166:2437-45.

[4] Rehm J, Mathers C, Popova S, Thavorncharoensap M, Teerawattananon Y, Patra J. Global burden of disease and injury and economic cost attributable to alcohol use and alcohol-use disorders. Lancet 2009;373:2223-33.

[5] Mukamal KJ, Ding EL, Djousse L. Alcohol consumption, physical activity, and chronic disease risk factors: a population-based cross-sectional survey. BMC Public Health 2006;6:118.

[6] Mukamal KJ, Girotra S, Mittleman MA. Alcohol consumption, atherosclerotic progression, and prognosis among patients with coronary artery bypass grafts. Am Heart J 2006;151:368-72.

[7] Hvidtfeldt UA, Tolstrup JS, Jakobsen MU, Heitmann BL, Gronbaek M, O'Reilly E, et al. Alcohol intake and risk of coronary heart disease in younger, middle-aged, and older adults. Circulation 2010;121:1589-97.

[8] Ronksley PE, Brien SE, Turner BJ, Mukamal KJ, Ghali WA. Association of alcohol consumption with selected cardiovascular disease outcomes: a systematic review and metaanalysis. BMJ 2011;342:d671.

[9] Malinski MK, Sesso HD, Lopez-Jimenez F, Buring JE, Gaziano JM. Alcohol consumption and cardiovascular disease mortality in hypertensive men. Arch Intern Med 2004;164: 623-8.

[10] Koppes LL, Dekker JM, Hendriks HF, Bouter LM, Heine RJ. Meta-analysis of the relationship between alcohol consumption and coronary heart disease and mortality in type 2 diabetic patients. Diabetologia 2006;49:648-52.

[11] Mukamal KJ. Alcohol use and prognosis in patients with coronary heart disease. Prev Cardiol 2003;6:93-8.

[12] Costanzo S, Di Castelnuovo A, Donati MB, lacoviello L, de Gaetano G. Alcohol consumption and mortality in patients with cardiovascular disease: a meta-analysis. J Am Coll Cardiol 2010;55:1339-47.

[13] Niroomand F, Hauer O, Tiefenbacher CP, Katus HA, Kuebler W. Influence of alcohol consumption on restenosis rate after percutaneous transluminal coronary angioplasty and stent implantation. Heart 2004;90:1189-93.

[14] Frost L, Vestergaard P. Alcohol and risk of atrial fibrillation or flutter: a cohort study. Arch Intern Med 2004;164: 1993-8.

[15] Balbao CE, de Paola AA, Fenelon G. Effects of alcohol on atrial fibrillation: myths and truths. Ther Adv Cardiovasc Dis 2009;3:53-63.

[16] Mukamal KJ, Maclure M, Muller JE, Mittleman MA. Binge drinking and mortality after acute myocardial infarction. Circulation 2005;112:3839-45.

[17] Kodama S, Saito K, Tanaka S, Horikawa C, Saito A, Heianza Y, et al. Alcohol consumption and risk of atrial fibrillation: a meta-analysis. J Am Coll Cardiol 2011;57:427-36.

[18] Albert CM, Manson JE, Cook NR, Ajani UA, Gaziano JM, Hennekens $\mathrm{CH}$. Moderate alcohol consumption and the risk of sudden cardiac death among US male physicians. Circulation 1999;100:944-50.

[19] Chiuve SE, Rimm EB, Mukamal KJ, Rexrode KM, Stampfer MJ, Manson JE, et al. Light-to-moderate alcohol consumption and risk of sudden cardiac death in women. Heart Rhythm 2010;7:1374-80.

[20] Reynolds K, Lewis B, Nolen JD, Kinney GL, Sathya B, He J. Alcohol consumption and risk of stroke: a meta-analysis. J Am Med Assoc 2003;289:579-88.

[21] Patra J, Taylor B, Irving H, Roerecke M, Baliunas D, Mohapatra S, et al. Alcohol consumption and the risk of morbidity and mortality for different stroke types-a systematic review and metaanalysis. BMC Public Health 2010;10:258.

[22] Jimenez M, Chiuve SE, Glynn RJ, Stampfer MJ, Camargo Jr CA, Willett WC, et al. Alcohol consumption and risk of stroke in women. Stroke 2012;43:939-45.

[23] Malarcher AM, Giles WH, Croft JB, Wozniak MA, Wityk RJ, Stolley PD, et al. Alcohol intake, type of beverage, and the risk of cerebral infarction in young women. Stroke 2001;32: 77-83.

[24] Di Castelnuovo A, Rotondo S, lacoviello L, Donati MB, De Gaetano G. Meta-analysis of wine and beer consumption in relation to vascular risk. Circulation 2002;105:2836-44. 
[25] Djousse L, Ellison RC, Beiser A, Scaramucci A, D’Agostino RB, Wolf PA. Alcohol consumption and risk of ischemic stroke: the Framingham Study. Stroke 2002;33:907-12.

[26] Sacco RL, Elkind M, Boden-Albala B, Lin IF, Kargman DE, Hauser WA, et al. The protective effect of moderate alcohol consumption on ischemic stroke. J Am Med Assoc 1999;281: 53-60.

[27] Myint PK, Luben RN, Wareham NJ, Bingham SA, Khaw KT. Combined effect of health behaviours and risk of first ever stroke in 20,040 men and women over 11 years' follow-up in Norfolk cohort of European Prospective Investigation of Cancer (EPIC Norfolk): prospective population study. BMJ 2009;338:b349.

[28] Jackson VA, Sesso HD, Buring JE, Gaziano JM. Alcohol consumption and mortality in men with preexisting cerebrovascular disease. Arch Intern Med 2003;163:1189-93.

[29] Higashiyama A, Wakabayashi I, Ono Y, Watanabe $M$, Kokubo Y, Okayama A, et al. Association with serum gammaglutamyltransferase levels and alcohol consumption on stroke and coronary artery disease: the Suita study. Stroke 2011;42:1764-7.

[30] Sundell L, Salomaa V, Vartiainen E, Poikolainen K, Laatikainen T. Increased stroke risk is related to a bingedrinking habit. Stroke 2008;39:3179-84.

[31] Potter JF, Beevers DG. Factors determining the acute pressor response to alcohol. Clin Exp Hypertens A 1991;13:13-34.

[32] Mostofsky E, Burger MR, Schlaug G, Mukamal KJ, Rosamond WD, Mittleman MA. Alcohol and acute ischemic stroke onset: the stroke onset study. Stroke 2010;41:1845-9.

[33] Maclure M. Demonstration of deductive meta-analysis: ethanol intake and risk of myocardial infarction. Epidemiol Rev 1993;15:328-51.

[34] Corrao G, Rubbiati L, Bagnardi V, Zambon A, Poikolainen K. Alcohol and coronary heart disease: a meta-analysis. Addiction 2000;95:1505-23.

[35] Dormandy J, Mahir M, Ascady G, Balsano F, De Leeuw P, Blombery $\mathrm{P}$, et al. Fate of the patient with chronic leg ischaemia. A review article. J Cardiovasc Surg (Torino) 1989; 30:50-7.

[36] Vliegenthart R, Geleijnse JM, Hofman A, Meijer WT, van Rooij FJ, Grobbee DE, et al. Alcohol consumption and risk of peripheral arterial disease: the Rotterdam study. Am J Epidemiol 2002;155:332-8.

[37] Fabsitz RR, Sidawy AN, Go O, Lee ET, Welty TK, Devereux RB, et al. Prevalence of peripheral arterial disease and associated risk factors in American Indians: the Strong Heart Study. Am J Epidemiol 1999;149:330-8.

[38] Jepson RG, Fowkes FG, Donnan PT, Housley E. Alcohol intake as a risk factor for peripheral arterial disease in the general population in the Edinburgh Artery Study. Eur J Epidemiol 1995;11:9-14.

[39] Whiteman MC, Deary IJ, Fowkes FG. Personality and social predictors of atherosclerotic progression: Edinburgh Artery Study. Psychosom Med 2000;62:703-14.

[40] Djousse L, Levy D, Murabito JM, Cupples LA, Ellison RC. Alcohol consumption and risk of intermittent claudication in the Framingham Heart Study. Circulation 2000;102:3092-7.

[41] Camargo Jr CA, Stampfer MJ, Glynn RJ, Gaziano JM, Manson JE, Goldhaber SZ, et al. Prospective study of moderate alcohol consumption and risk of peripheral arterial disease in US male physicians. Circulation 1997;95:577-80.

[42] Ciccarone E, Di Castelnuovo A, Salcuni M, Siani A, Giacco A, Donati MB, et al. A high-score Mediterranean dietary pattern is associated with a reduced risk of peripheral arterial disease in Italian patients with Type 2 diabetes. J Thromb Haemost 2003;1:1744-52.

[43] Tornwall ME, Virtamo J, Haukka JK, Albanes D, Huttunen JK. Life-style factors and risk for abdominal aortic aneurysm in a cohort of Finnish male smokers. Epidemiology 2001;12: 94-100.

[44] Rimm EB, Williams P, Fosher K, Criqui M, Stampfer MJ. Moderate alcohol intake and lower risk of coronary heart disease: meta-analysis of effects on lipids and haemostatic factors. BMJ 1999;319:1523-8.

[45] Nishiwaki $M$, Ishikawa $T$, Ito $T$, Shige $H$, Tomiyasu $K$, Nakajima K, et al. Effects of alcohol on lipoprotein lipase, hepatic lipase, cholesteryl ester transfer protein, and lecithin:cholesterol acyltransferase in high-density lipoprotein cholesterol elevation. Atherosclerosis 1994;111:99-109.

[46] Belleville J. The French paradox: possible involvement of ethanol in the protective effect against cardiovascular diseases. Nutrition 2002;18:173-7.

[47] van Leuven SI, Stroes ES, Kastelein JJ. High-density lipoprotein: a fall from grace? Annu Med 2008;40:584-93.

[48] Farmer JA, Liao J. Evolving concepts of the role of highdensity lipoprotein in protection from atherosclerosis. Curr Atheroscler Rep 2011;13:107-14.

[49] Brien SE, Ronksley PE, Turner BJ, Mukamal KJ, Ghali WA. Effect of alcohol consumption on biological markers associated with risk of coronary heart disease: systematic review and meta-analysis of interventional studies. BMJ 2011;342: d636.

[50] Klatsky AL, Friedman GD, Armstrong MA. The relationships between alcoholic beverage use and other traits to blood pressure: a new Kaiser Permanente study. Circulation 1986;73:628-36.

[51] Zilkens RR, Burke V, Hodgson JM, Barden A, Beilin LJ, Puddey IB. Red wine and beer elevate blood pressure in normotensive men. Hypertension 2005;45:874-9.

[52] Fuchs FD, Chambless LE, Whelton PK, Nieto FJ, Heiss G. Alcohol consumption and the incidence of hypertension: the Atherosclerosis Risk in Communities Study. Hypertension 2001;37:1242-50.

[53] Klatsky AL, Friedman GD, Siegelaub AB, Gerard MJ. Alcohol consumption and blood pressure Kaiser-Permanente Multiphasic Health Examination data. N Engl J Med 1977;296: 1194-200.

[54] Gillman MW, Cook NR, Evans DA, Rosner B, Hennekens CH. Relationship of alcohol intake with blood pressure in young adults. Hypertension 1995;25:1106-10.

[55] Primatesta P, Brookes M, Poulter NR. Improved hypertension management and control: results from the health survey for England 1998. Hypertension 2001;38:827-32.

[56] Hillbom M, Saloheimo P, Juvela S. Alcohol consumption, blood pressure, and the risk of stroke. Curr Hypertens Rep 2011;13:208-13.

[57] Kawano Y. Physio-pathological effects of alcohol on the cardiovascular system: its role in hypertension and cardiovascular disease. Hypertens Res 2010;33:181-91.

[58] Sesso HD, Cook NR, Buring JE, Manson JE, Gaziano JM. Alcohol consumption and the risk of hypertension in women and men. Hypertension 2008;51:1080-7.

[59] Chen L, Davey Smith G, Harbord RM, Lewis SJ. Alcohol intake and blood pressure: a systematic review implementing a Mendelian randomization approach. PLoS Med 2008;5:e52.

[60] Teragawa H, Fukuda Y, Matsuda K, Higashi Y, Yamagata T, Matsuura $\mathrm{H}$, et al. Effect of alcohol consumption on endothelial function in men with coronary artery disease. Atherosclerosis 2002;165:145-52.

[61] Corder R, Douthwaite JA, Lees DM, Khan NQ, Viseu Dos Santos AC, Wood EG, et al. Endothelin-1 synthesis reduced by red wine. Nature 2001;414:863-4.

[62] Agewall S, Wright S, Doughty RN, Whalley GA, Duxbury M, Sharpe N. Does a glass of red wine improve endothelial function? Eur Heart J 2000;21:74-8.

[63] Karatzi K, Papamichael C, Aznaouridis K, Karatzis E, Lekakis J, Matsouka C, et al. Constituents of red wine other 
than alcohol improve endothelial function in patients with coronary artery disease. Coron Artery Dis 2004;15:485-90.

[64] Duarte J, Andriambeloson E, Diebolt M, Andriantsitohaina R. Wine polyphenols stimulate superoxide anion production to promote calcium signaling and endothelial-dependent vasodilatation. Physiol Res 2004;53:595-602.

[65] Karatzi K, Karatzis E, Papamichael C, Lekakis J, Zampelas A. Effects of red wine on endothelial function: postprandial studies vs clinical trials. Nutr Metab Cardiovasc Dis 2009;19: 744-50.

[66] Fuchs FD. Vascular effects of alcoholic beverages: is it only alcohol that matters? Hypertension 2005;45:851-2.

[67] Kloner RA, Rezkalla SH. To drink or not to drink? That is the question. Circulation 2007;116:1306-17.

[68] Pai JK, Hankinson SE, Thadhani R, Rifai N, Pischon T, Rimm EB. Moderate alcohol consumption and lower levels of inflammatory markers in US men and women. Atherosclerosis 2006;186:113-20.

[69] Imhof A, Froehlich $M$, Brenner $H$, Boeing $H$, Pepys $M B$, Koenig W. Effect of alcohol consumption on systemic markers of inflammation. Lancet 2001;357:763-7.

[70] Imhof A, Woodward M, Doering A, Helbecque N, Loewel $H$, Amouyel $\mathrm{P}$, et al. Overall alcohol intake, beer, wine, and systemic markers of inflammation in western Europe: results from three MONICA samples (Augsburg, Glasgow, Lille). Eur Heart J 2004;25:2092-100.

[71] Volpato S, Pahor M, Ferrucci L, Simonsick EM, Guralnik JM, Kritchevsky SB, et al. Relationship of alcohol intake with inflammatory markers and plasminogen activator inhibitor-1 in well-functioning older adults: the Health, Aging, and Body Composition study. Circulation 2004;109:607-12.

[72] Shai I, Rimm EB, Schulze MB, Rifai N, Stampfer MJ, Hu FB. Moderate alcohol intake and markers of inflammation and endothelial dysfunction among diabetic men. Diabetologia 2004;47:1760-7.

[73] Kaptoge S, White IR, Thompson SG, Wood AM, Lewington S, Lowe GD, et al. Associations of plasma fibrinogen levels with established cardiovascular disease risk factors, inflammatory markers, and other characteristics: individual participant meta-analysis of 154,211 adults in 31 prospective studies: the fibrinogen studies collaboration. Am J Epidemiol 2007; 166:867-79.

[74] Beulens JW, van Beers RM, Stolk RP, Schaafsma G, Hendriks HF. The effect of moderate alcohol consumption on fat distribution and adipocytokines. Obes (Silver Spring) 2006;14:60-6.

[75] Riera-Guardia N, Rothenbacher D. The effect of thiazolidinediones on adiponectin serum level: a meta-analysis. Diabetes Obes Metab 2008;10:367-75.

[76] Visioli F. Nutritional support in the pharmacological treatment of metabolic syndrome. Eur J Pharmacol 2011; 668(Suppl. 1):S43-9.

[77] Fujita N, Takei Y. Alcohol consumption and metabolic syndrome. Hepatol Res 2011;41:287-95.

[78] Freiberg MS, Cabral HJ, Heeren TC, Vasan RS, Curtis Ellison R. Alcohol consumption and the prevalence of the Metabolic Syndrome in the US.: a cross-sectional analysis of data from the Third National Health and Nutrition Examination Survey. Diabetes Care 2004;27:2954-9.

[79] Buja A, Scafato E, Sergi G, Maggi S, Suhad MA, Rausa G, et al. Alcohol consumption and metabolic syndrome in the elderly: results from the Italian longitudinal study on aging. Eur J Clin Nutr 2010;64:297-307.

[80] Alkerwi A, Boutsen M, Vaillant M, Barre J, Lair ML, Albert A, et al. Alcohol consumption and the prevalence of metabolic syndrome: a meta-analysis of observational studies. Atherosclerosis 2009;204:624-35.

[81] Lazarus R, Sparrow D, Weiss ST. Alcohol intake and insulin levels. The Normative Aging Study. Am J Epidemiol 1997;145:909-16.
[82] Kiechl S, Willeit J, Poewe W, Egger G, Oberhollenzer F, Muggeo $M$, et al. Insulin sensitivity and regular alcohol consumption: large, prospective, cross sectional population study (Bruneck study). BMJ 1996;313:1040-4.

[83] Riserus U, Ingelsson E. Alcohol intake, insulin resistance, and abdominal obesity in elderly men. Obes (Silver Spring) 2007; 15:1766-73.

[84] Yokoyama H. Beneficial effects of ethanol consumption on insulin resistance are only applicable to subjects without obesity or insulin resistance; drinking is not necessarily a remedy for metabolic syndrome. Int J Environ Res Public Health 2011;8:3019-31.

[85] Davies MJ, Baer DJ, Judd JT, Brown ED, Campbell WS, Taylor PR. Effects of moderate alcohol intake on fasting insulin and glucose concentrations and insulin sensitivity in postmenopausal women: a randomized controlled trial. J Am Med Assoc 2002;287:2559-62.

[86] Joosten MM, Beulens JW, Kersten S, Hendriks HF. Moderate alcohol consumption increases insulin sensitivity and ADIPOQ expression in postmenopausal women: a randomised, crossover trial. Diabetologia 2008;51:1375-81.

[87] Beulens JW, de Zoete EC, Kok FJ, Schaafsma G, Hendriks HF. Effect of moderate alcohol consumption on adipokines and insulin sensitivity in lean and overweight men: a diet intervention study. Eur J Clin Nutr 2008;62:1098-105.

[88] Yeomans MR. Alcohol, appetite and energy balance: is alcohol intake a risk factor for obesity? Physiol Behav 2010; 100:82-9.

[89] Wannamethee SG, Field AE, Colditz GA, Rimm EB. Alcohol intake and 8-year weight gain in women: a prospective study. Obes Res 2004;12:1386-96.

[90] Wang L, Lee IM, Manson JE, Buring JE, Sesso HD. Alcohol consumption, weight gain, and risk of becoming overweight in middle-aged and older women. Arch Intern Med 2010;170: 453-61.

[91] Arif AA, Rohrer JE. Patterns of alcohol drinking and its association with obesity: data from the Third National Health and Nutrition Examination Survey, 1988-1994. BMC Public Health 2005;5:126.

[92] Greenfield JR, Samaras K, Jenkins AB, Kelly PJ, Spector TD, Campbell LV. Moderate alcohol consumption, dietary fat composition, and abdominal obesity in women: evidence for gene-environment interaction. J Clin Endocrinol Metab 2003; 88:5381-6.

[93] Sayon-Orea C, Martinez-Gonzalez MA, Bes-Rastrollo M. Alcohol consumption and body weight: a systematic review. Nutr Rev 2011;69:419-31.

[94] Koppes LL, Dekker JM, Hendriks HF, Bouter LM, Heine RJ. Moderate alcohol consumption lowers the risk of type 2 diabetes: a meta-analysis of prospective observational studies. Diabetes Care 2005;28:719-25.

[95] Hodge AM, English DR, O’Dea K, Giles GG. Alcohol intake, consumption pattern and beverage type, and the risk of Type 2 diabetes. Diabet Med 2006;23:690-7.

[96] Valmadrid CT, Klein R, Moss SE, Klein BE, Cruickshanks KJ. Alcohol intake and the risk of coronary heart disease mortality in persons with older-onset diabetes mellitus. J Am Med Assoc 1999;282:239-46.

[97] Beulens JW, Algra A, Soedamah-Muthu SS, Visseren FL, Grobbee DE, van der Graaf Y. Alcohol consumption and risk of recurrent cardiovascular events and mortality in patients with clinically manifest vascular disease and diabetes mellitus: the Second Manifestations of ARTerial (SMART) disease study. Atherosclerosis 2010;212:281-6.

[98] Djousse L, Lee IM, Buring JE, Gaziano JM. Alcohol consumption and risk of cardiovascular disease and death in women: potential mediating mechanisms. Circulation 2009;120: 237-44. 
[99] Standards of medical care in diabetes-2010. Diabetes Care 2010;33(Suppl. 1):S11-61.

[100] Ratziu V, Bellentani S, Cortez-Pinto H, Day C, Marchesini G. A position statement on NAFLD/NASH based on the EASL 2009 special conference. J Hepatol 2010;53:372-84.

[101] O'Shea RS, Dasarathy S, McCullough AJ. Alcoholic liver disease. Hepatology 2010;51:307-28.

[102] Bellentani S, Scaglioni F, Marino M, Bedogni G. Epidemiology of non-alcoholic fatty liver disease. Dig Dis 2010;28:155-61.

[103] Brick J. Standardization of alcohol calculations in research. Alcohol Clin Exp Res 2006;30:1276-87.

[104] Bellentani S, Saccoccio G, Masutti F, Croce LS, Brandi G, Sasso $F$, et al. Prevalence of and risk factors for hepatic steatosis in Northern Italy. Ann Intern Med 2000;132:112-7.

[105] Becker U, Gronbaek M, Johansen D, Sorensen TI. Lower risk for alcohol-induced cirrhosis in wine drinkers. Hepatology 2002;35:868-75.

[106] Dunn W, Sanyal AJ, Brunt EM, Unalp-Arida A, Donohue M, McCullough AJ, et al. Modest alcohol consumption is associated with decreased prevalence of steatohepatitis in patients with non-alcoholic fatty liver disease (NAFLD). J Hepatol 2012;57:384-91.

[107] Dunn W, Xu R, Schwimmer JB. Modest wine drinking and decreased prevalence of suspected nonalcoholic fatty liver disease. Hepatology 2008;47:1947-54.

[108] Targher G, Day CP, Bonora E. Risk of cardiovascular disease in patients with nonalcoholic fatty liver disease. N Engl J Med 2010;363:1341-50.

[109] Howard AA, Arnsten JH, Gourevitch MN. Effect of alcohol consumption on diabetes mellitus: a systematic review. Ann Intern Med 2004;140:211-9.

[110] Gao B, Bataller R. Alcoholic liver disease: pathogenesis and new therapeutic targets. Gastroenterology 2011;141:1572-85.

[111] Ruitenberg A, van Swieten JC, Witteman JC, Mehta KM, van Duijn CM, Hofman A, et al. Alcohol consumption and risk of dementia: the Rotterdam Study. Lancet 2002;359:281-6.

[112] Luchsinger JA, Tang MX, Siddiqui M, Shea S, Mayeux R. Alcohol intake and risk of dementia. J Am Geriatr Soc 2004; 52:540-6.

[113] Ganguli M, Vander Bilt J, Saxton JA, Shen C, Dodge $H H$. Alcohol consumption and cognitive function in late life: a longitudinal community study. Neurology 2005;65:1210-7.

[114] Solfrizzi V, D'Introno A, Colacicco AM, Capurso C, Del Parigi A, Baldassarre G, et al. Alcohol consumption, mild cognitive impairment, and progression to dementia. Neurology 2007;68:1790-9.

[115] Weyerer S, Schaufele M, Wiese B, Maier W, Tebarth F, van den Bussche $\mathrm{H}$, et al. Current alcohol consumption and its relationship to incident dementia: results from a 3-year follow-up study among primary care attenders aged 75 years and older. Age Ageing 2011;40:456-63.

[116] Peters R, Peters J, Warner J, Beckett N, Bulpitt C. Alcohol, dementia and cognitive decline in the elderly: a systematic review. Age Ageing 2008;37:505-12.

[117] Anstey KJ, Mack HA, Cherbuin N. Alcohol consumption as a risk factor for dementia and cognitive decline: meta-analysis of prospective studies. Am J Geriatr Psychiatry 2009;17: 542-55.

[118] Reitz C, Brayne C, Mayeux R. Epidemiology of Alzheimer disease. Nat Rev Neurol 2011;7:137-52.

[119] Bate C, Williams A. Ethanol protects cultured neurons against amyloid-beta and alpha-synuclein-induced synapse damage. Neuropharmacology 2011;61:1406-12.

[120] Maurel DB, Boisseau N, Benhamou CL, Jaffre C. Alcohol and bone: review of dose effects and mechanisms. Osteoporos Int 2012;23:1-16.

[121] McLernon DJ, Powell JJ, Jugdaohsingh R, Macdonald HM. Do lifestyle choices explain the effect of alcohol on bone mineral density in women around menopause? Am J Clin Nutr 2012;95:1261-9.

[122] Tucker KL, Jugdaohsingh R, Powell JJ, Qiao N, Hannan MT, Sripanyakorn $\mathrm{S}$, et al. Effects of beer, wine, and liquor intakes on bone mineral density in older men and women. Am J Clin Nutr 2009;89:1188-96.

[123] Williams FM, Cherkas LF, Spector TD, MacGregor AJ. The effect of moderate alcohol consumption on bone mineral density: a study of female twins. Ann Rheum Dis 2005;64:309-10.

[124] Fanti P, Monier-Faugere MC, Geng Z, Cohen D, Malluche HH. Moderately high consumption of ethanol suppresses bone resorption in ovariectomized but not in sexually intact adult female rats. Alcohol Clin Exp Res 1997;21:1150-4.

[125] Berg KM, Kunins HV, Jackson JL, Nahvi S, Chaudhry A, Harris Jr KA, et al. Association between alcohol consumption and both osteoporotic fracture and bone density. Am J Med 2008;121:406-18.

[126] Hoidrup S, Gronbaek M, Gottschau A, Lauritzen JB, Schroll M. Alcohol intake, beverage preference, and risk of hip fracture in men and women. Copenhagen Centre for Prospective Population Studies. Am J Epidemiol 1999;149:993-1001.

[127] Kanis JA, Oden A, Johansson H, Borgstrom F, Strom O, McCloskey E. FRAX and its applications to clinical practice. Bone 2009;44:734-43.

[128] IARC. Alcohol consumption and ethyl carbamate. Lyon, France: International Agency for Research on Cancer; 2010.

[129] Pelucchi C, Tramacere I, Boffetta P, Negri E, La Vecchia C. Alcohol consumption and cancer risk. Nutr Cancer 2011;63: 983-90.

[130] Enzinger PC, Mayer RJ. Esophageal cancer. N Engl J Med 2003;349:2241-52.

[131] Bagnardi V, Blangiardo M, La Vecchia C, Corrao G. A metaanalysis of alcohol drinking and cancer risk. $\mathrm{Br} \mathrm{J}$ Cancer 2001;85:1700-5.

[132] Poli A, Marangoni F, Visioli F. Alcohol consumption and breast cancer risk. J Am Med Assoc 2012;307:666 [author reply 666].

[133] Fedirko V, Tramacere I, Bagnardi V, Rota M, Scotti L, Islami F, et al. A meta-analysis of alcohol drinking and colorectal cancer risk: a dose-response analysis of published studies. Ann Oncol 2011;22:1958-72.

[134] Islami F, Fedirko V, Tramacere I, Bagnardi V, Jenab M, Scotti $L$, et al. Alcohol drinking and esophageal squamous cell carcinoma with focus on light-drinkers and neversmokers - a systematic review and meta-analysis. Int $J$ Cancer 2011;129:2473-84.

[135] Islami F, Tramacere I, Rota M, Bagnardi V, Fedirko V, Scotti L, et al. Alcohol drinking and laryngeal cancer: overall and dose-risk relation-a systematic review and meta-analysis. Oral Oncol 2010;46:802-10.

[136] Tramacere I, Negri E, Bagnardi V, Garavello W, Rota M, Scotti L, et al. A meta-analysis of alcohol drinking and oral and pharyngeal cancers. Part 1: overall results and dose-risk relation. Oral Oncol 2010;46:497-503.

[137] Tramacere I, Scotti L, Jenab M, Bagnardi V, Bellocco R, Rota $M$, et al. Alcohol drinking and pancreatic cancer risk: a meta-analysis of the dose-risk relation. Int J Cancer 2010; 126:1474-86.

[138] Hamajima N, Hirose K, Tajima K, Rohan T, Calle EE, Heath Jr CW, et al. Alcohol, tobacco and breast cancer-collaborative reanalysis of individual data from 53 epidemiological studies, including 58,515 women with breast cancer and 95,067 women without the disease. Br J Cancer 2002;87:1234-45.

[139] Allen NE, Beral V, Casabonne D, Kan SW, Reeves GK, Brown A, et al. Moderate alcohol intake and cancer incidence in women. J Natl Cancer Inst 2009;101:296-305.

[140] Turati F, Garavello W, Tramacere I, Bagnardi V, Rota M, Scotti L, et al. A meta-analysis of alcohol drinking and oral 
and pharyngeal cancers. Part 2: results by subsites. Oral Oncol 2010;46:720-6.

[141] Michaud DS, Vrieling A, Jiao L, Mendelsohn JB, Steplowski E, Lynch SM, et al. Alcohol intake and pancreatic cancer: a pooled analysis from the pancreatic cancer cohort consortium (PanScan). Cancer Causes Control 2010;21:1213-25.

[142] Boffetta P, Hashibe M, La Vecchia C, Zatonski W, Rehm J. The burden of cancer attributable to alcohol drinking. Int J Cancer 2006;119:884-7.

[143] Boyle P, Autier P, Bartelink H, Baselga J, Boffetta P, Burn J, et al. European code against cancer and scientific justification: third version (2003). Ann Oncol 2003;14:973-1005.

[144] Thun MJ, Peto R, Lopez AD, Monaco JH, Henley SJ, Heath Jr CW, et al. Alcohol consumption and mortality among middle-aged and elderly U.S. adults. N Engl J Med 1997;337:1705-14.

[145] Costanzo S, Di Castelnuovo A, Donati MB, lacoviello L, de Gaetano G. Cardiovascular and overall mortality risk in relation to alcohol consumption in patients with cardiovascular disease. Circulation 2010;121:1951-9.

[146] Rosenbloom JI, Mukamal KJ, Frost LE, Mittleman MA. Alcohol consumption patterns, beverage type, and long-term mortality among women survivors of acute myocardial infarction. Am J Cardiol 2012;109:147-52.

[147] Holahan CJ, Schutte KK, Brennan PL, Holahan CK, Moos BS, Moos RH. Late-life alcohol consumption and 20-year mortality. Alcohol Clin Exp Res 2010;34:1961-71.

[148] Estruch R, Sacanella E, Mota F, Chiva-Blanch G, Antunez E, Casals $\mathrm{E}$, et al. Moderate consumption of red wine, but not gin, decreases erythrocyte superoxide dismutase activity: a randomised cross-over trial. Nutr Metab Cardiovasc Dis 2011; 21:46-53.

[149] Visioli F, De La Lastra CA, Andres-Lacueva C, Aviram M, Calhau C, Cassano A, et al. Polyphenols and human health: a prospectus. Crit Rev Food Sci Nutr 2011;51:524-46.

[150] Di Castelnuovo A, Costanzo S, di Giuseppe R, de Gaetano G, lacoviello L. Alcohol consumption and cardiovascular risk: mechanisms of action and epidemiologic perspectives. Future Cardiol 2009;5:467-77.

[151] Rotches-Ribalta M, Andres-Lacueva C, Estruch R, Escribano E, Urpi-Sarda M. Pharmacokinetics of resveratrol metabolic profile in healthy humans after moderate consumption of red wine and grape extract tablets. Pharmacol Res 2012;66:375-82.

[152] Noguer MA, Cerezo AB, Donoso Navarro E, Garcia-Parrilla MC. Intake of alcohol-free red wine modulates antioxidant enzyme activities in a human intervention study. Pharmacol Res 2012;65:609-14.

[153] Ou HC, Chou FP, Sheen HM, Lin TM, Yang CH, Huey-Herng Sheu W. Resveratrol, a polyphenolic compound in red wine, protects against oxidized LDL-induced cytotoxicity in endothelial cells. Clin Chim Acta 2006;364:196-204.

[154] Rotondo S, Rotilio D, Cerletti C, de Gaetano G. Red wine, aspirin and platelet function. Thromb Haemost 1996;76: 818-9.

[155] Wollny T, Aiello L, Di Tommaso D, Bellavia V, Rotilio D, Donati $\mathrm{MB}$, et al. Modulation of haemostatic function and prevention of experimental thrombosis by red wine in rats: $a$ role for increased nitric oxide production. $\mathrm{Br} \mathrm{J}$ Pharmacol 1999;127:747-55.

[156] di Giuseppe R, de Lorgeril M, Salen P, Laporte F, Di Castelnuovo A, Krogh V, et al. Alcohol consumption and n-3 polyunsaturated fatty acids in healthy men and women from 3 European populations. Am J Clin Nutr 2009;89: 354-62.

[157] Corrao G, Bagnardi V, Zambon A, Arico S. Exploring the doseresponse relationship between alcohol consumption and the risk of several alcohol-related conditions: a meta-analysis. Addiction 1999;94:1551-73.

[158] Rimm EB, Klatsky A, Grobbee D, Stampfer MJ. Review of moderate alcohol consumption and reduced risk of coronary heart disease: is the effect due to beer, wine, or spirits. BMJ 1996;312:731-6.

[159] Costanzo S, Di Castelnuovo A, Donati MB, lacoviello L, de Gaetano G. Wine, beer or spirit drinking in relation to fatal and non-fatal cardiovascular events: a meta-analysis. Eur J Epidemiol 2011;26:833-50.

[160] Mukamal KJ, Conigrave KM, Mittleman MA, Camargo Jr CA, Stampfer MJ, Willett WC, et al. Roles of drinking pattern and type of alcohol consumed in coronary heart disease in men. $\mathrm{N}$ Engl J Med 2003;348:109-18. 